\title{
Magmatismos shoshonítico e cálcio-alcalino de alto potássio pós-orogênico (615 Ma) na porção leste do Domínio Macururé, Sistema Orogênico Sergipano: Stocks Propriá, Amparo do São Francisco e Fazenda Alvorada Shoshonitic and calc-alcaline high potassic post-orogenic (615 Ma) magmatism in the eastern part of Macururé Domain, Sergipan Orogenic System: Propriá, Amparo do São Francisco and Fazenda Alvorada Stocks
}

\begin{abstract}
Ítalo Santana Santos ${ }^{1,2}$ (D), Herbet Conceição,,2 (D), Maria de Lourdes da Silva Rosa ${ }^{1,2}$ (D), Moacyr Moura Marinho 3 ${ }^{1} U$ niversidade Federal de Sergipe - UFS, Programa de Pós-Graduação em Geociências e Análise de Bacias - PGAB, Galpão das Geociências, Cidade Universitária, Prof. José Aloísio de Campos, Avenida Marechal Rondon, s/n., Jardim Rosa Elze, CEP 49100-000, São Cristóvão, SE, BR (sn_italo@ymail.com; herbet@ufs.br; Irosa@ufs.br) ¿Universidade Federal de Sergipe - UFS, Laboratório de Petrologia Aplicada à Pesquisa Mineral - LAPA, São Cristóvão, SE, BR 3Universidade Federal da Bahia - UFBA, Instituto de Geociências - IG, Salvador, BA, BR (mmm@ufba.br)
\end{abstract}

Recebido em 5 de dezembro de 2017; aceito em 19 de fevereiro de 2019

\begin{abstract}
Resumo
Os Stocks Propriá, Amparo do São Francisco e Fazenda Alvorada são intrusivos na parte leste do Domínio Macururé e truncam a foliação regional. Esses corpos apresentam feições geológicas e petrográficas semelhantes e são composicionalmente constituídos por quartzo monzonitos e granitos porfiríticos. Nesses plutons, a biotita é o mineral máfico predominante e hornblenda ocorre em alguns enclaves associados. Os cristais de plagioclásio exibem forte zoneamento, indicando instabilidades durante a cristalização magmática. Os minerais acessórios nessas rochas são apatita, zircão, titanita, minerais opacos. Nos Stocks Propriá e Amparo do São Francisco enclaves máficos microgranulares são abundantes. A idade de cristalização do Stock Propriá é de $615 \pm 6 \mathrm{Ma}\left(\mathrm{U}_{-} \mathrm{Pb}_{\text {Shrimp }}\right)$. Os dados geoquímicos indicam que esses stocks correspondem a magmas potássicos, gerados em ambiente orogênico e alojados na crosta em período pós-colisional.
\end{abstract}

Palavras-chave: Granitos; Idade U-Pb; Petrografia; Geoquímica.

\begin{abstract}
The Propriá, Amparo do São Francisco and Fazenda Alvorada Stocks are intrusive in the eastern part of the Macururé Domain and cross-cut the regional trend. These stocks present similar geological and petrographic features and are constituted by quartz monzonites and porphyritic granites. In these plutons, biotite is the predominant mafic mineral and hornblende occurs in some enclaves. Plagioclase crystals exhibit patchy zoning, indicating important instabilities during crystallization. The accessory minerals in these rocks are apatite, zircon, titanite, opaque minerals. In the Propriá and Amparo do São Francisco stocks, the microgranular mafic enclaves are abundant. The crystallization age of the Propria Stock is $615 \pm 6 \mathrm{Ma}$ $\left(\mathrm{U}-\mathrm{Pb}_{\text {Shrimp }}\right)$. Geochemical data indicate that these stocks represent potassic magmas, generated in an orogenic environment and later intrusive in the post-collision period.
\end{abstract}

Keywords: Granites; U-Pb Age; Petrography; Geochemistry. 


\section{INTRODUÇÃO}

O Domínio Macururé localiza-se na parte central do Sistema Orogênico Sergipano (SOS) e representa o limite sul da Província Borborema com o Cráton do São Francisco. Esse domínio é essencialmente metapelítico (Silva Filho et al., 1979), sendo interpretado como uma cunha turbidítica (Jardim de Sá et al., 1981) com até $13 \mathrm{~km}$ de espessura (Del'Rey et al., 1995). Nos terrenos metassedimentares do Domínio Macururé existem cerca de 60 intrusões graníticas (lato sensu) que apresentam grande variedade de tipos petrográficos (e.g., Humphrey e Allard, 1969; Silva Filho et al., 1979; Gava et al., 1983; Santos et al., 2001; Teixeira, 2014), refletindo, provavelmente, a presença de magmas de diferentes fontes.

O SOS é interpretado como produto da Colisão Brasiliana/ Pan-Africana entre o Cráton do São Francisco, ao sul, e o Superterreno Pernambuco-Alagoas, ao norte (Van Schmus et al., 2008; Oliveira et al., 2010).

As idades de cristalização disponíveis para os granitos no Domínio Macururé variam de $571 \pm 9$ Ma (Bueno et al., 2009) até $631 \pm 5 \mathrm{Ma}$ (Rosa et al., 2017), e o clímax da Colisão Brasiliana/Pan-Africana tem sido alocado entre 570 e $590 \mathrm{Ma}$ (Bueno et al., 2009; Oliveira et al., 2017). O conjunto mais antigo de granitos é interpretado como magmatismo associado a um arco vulcânico e os granitos mais novos são interpretados como sincrônicos à Colisão Brasiliana entre continentes São Francisco e Bloco Pernambuco-Alagoas (Oliveira et al., 2017).

Conceição et al. (2016) chamam a atenção para o fato de a granitogênese no Domínio Macururé ter assinatura de arco magmático, sendo essencialmente formada por magmatismo cálcio-alcalino de alto potássio e, de forma subordinada, por rochas shoshoníticas, ultrapotássicas, cálcio-alcalinas de médio potássio e granitos peraluminosos.

Estudos sistemáticos de detalhe em intrusões graníticas (geologia, petrografia, geoquímica e geocronologia) no Domínio Macururé estão sendo realizados por pesquisadores da Universidade Federal de Sergipe (UFS). Este trabalho representa um desses produtos. Nele são apresentados e discutidos dados geológicos, petrográficos e geoquímicos de três stocks: Propriá, Amparo do São Francisco e Fazenda Alvorada, localizados na parte leste desse domínio, bem como a idade U-Pb $\mathrm{PHRIMP}_{\text {Sh }}$ Stock Propriá (SP). Pretende-se, com este trabalho, apresentar novos dados geológicos e os primeiros dados petrográficos, de química mineral e geoquímicos para esses stocks e, com essas novas informações, demonstrar o timing da cristalização dessas rochas e seu significado na Orogenia Brasiliana/Pan-Africana.

\section{CONTEXTO GEOLÓGICO REGIONAL}

A área de estudo localiza-se nos terrenos do SOS, situado na porção sul da Província Borborema (Van Schmus et al., 2008;
Brito Neves et al., 2014). Os terrenos do SOS apresentam-se como um conjunto de faixas orientadas NW-SE e limitadas por zonas de cisalhamentos (Figura 1). Essa disposição é atribuída ao resultado de Colisão Neoproterozoica entre o Cráton do São Francisco, localizado ao sul, e os terrenos do Maciço Pernambuco-Alagoas, localizados ao norte (Santos et al., 1988; Del'Rey et al., 1995; Bueno et al., 2009).

A identificação e a caracterização dos domínios geológicos no SOS foram elaboradas por Davison e Santos (1989) e Del'Rey et al. (1995). Os limites geológicos entre esses domínios correspondem a zonas de cisalhamentos e no interior desses terrenos têm-se indicadores estruturais de deslocamento de massa para sudeste (e.g., Silva Filho et al., 1978; Jardim de Sá et al., 1981). Esses domínios são, de sul para norte: Estância, Vaza Barris, Macururé, Marancó, Poço Redondo e Canindé. Os domínios Estância e Vaza Barris são metassedimentares e não têm descrita a presença de rochas ígneas plutônicas, existindo apenas modestas ocorrências de rochas vulcânicas (Silva Filho et al., 1979).

O Domínio Macururé, onde ocorrem os stocks deste estudo, é constituído de rochas metassedimentares (e.g., filito, ardósia, biotita xisto), com localizadas ocorrências de quartzitos, rochas cálcio-silicáticas e metavulcânicas, bem como mármores (Silva Filho et al., 1979; Santos et al., 2001). O Domínio Marancó é constituído de terrenos vulcanossedimentares e por gnaisse-granítico toniano (980-960 Ma) com geoquímica de granitos do tipo A (Carvalho, 2005). O Domínio Poço Redondo é formado por rochas gnáissico-migmatíticas tonianas e vulcanossedimentares (Carvalho, 2005). O Domínio Canindé é formado por intrusões máficas e ultramáficas mineralizadas com $\mathrm{Cu}$ e sequências vulcanossedimentares com granitos diversos (Silva Filho, 1976; Silva Filho et al., 1979; Oliveira e Tarney, 1990).

Os Domínios Macururé, Marancó, Poço Redondo e Canindé apresentam expressivo número de intrusões graníticas cujas idades variam de $631 \mathrm{Ma}$ a $570 \mathrm{Ma}$ (Carvalho, 2005; Long et al., 2005; Bueno et al., 2009; Rosa et al., 2017) e alguns corpos máfico-ultramáficos. Parte desse magmatismo granítico tem sido correlacionada à Colisão Brasiliana posicionada entre $590 \mathrm{Ma}$ e $570 \mathrm{Ma}$ (Bueno et al., 2009; Oliveira et al., 2017).

Teixeira (2014), ao elaborar o mais recente mapa geológico de Sergipe, integrou as informações disponíveis sobre a granitogênese no SOS, abandonou a utilização da terminologia "tipo" e agrupou os granitos em suítes. No Domínio Macururé, esse mesmo autor reconhece a presença de quatro suítes distintas e nomeadas como: Glória Xingó 2 (granitos com muscovita, por vezes com turmalina e granada); Glória-Xingo 1 (granitos equigranulares com duas micas); Queimada-Grande (biotita granitos e monzonitos); e Coronel João Sá (granitos e granodioritos).

Conceição et al. (2016), ao integrar os dados geoquímicos disponíveis sobre os granitos do Domínio Macururé, 
identificaram, em todos, assinatura orogênica e os reuniram em quatro conjuntos distintos:

- granodiorítico cálcio-alcalino de alto potássio;

- monzonítico shoshonítico;

- sienogranítico leucocrático cálcio-alcalino de alto potássio;

- granítico cálcio-alcalino com textura rapakivi.

Mendonça (2016) estudou três corpos graníticos (Canhoba, Gravata e Lagoa do Mato) localizados nas proximidades dos stocks deste estudo (Figura 2). Dois stocks (Canhoba e Gravata) correspondem a granitos a duas micas com afinidade cálcio-alcalina de alto potássio e o outro stock (Lagoa do Mato) tem composição monzonítica e afinidade shoshonítica.
Os stocks em estudo [Stock Propriá (SP), Amparo do São Francisco (SASF) e Fazenda Alvorada (SFA)] são, segundo Conceição et al. (2016), classificados como cálcio-alcalinos com textura rapakivi. As idades disponíveis na literatura sobre o SP são $606 \pm 16 \mathrm{Ma}$ (K-Ar em biotita, Almeida et al., 1968) e 643 $\pm 72 \mathrm{Ma}$ (Rb-Sr em rocha total, Brito Neves e Cordani, 1973).

\section{MÉTODOS DE ESTUDO}

No total, 30 amostras de rochas foram coletadas; destas, 19 foram selecionadas para estudos petrográficos e geoquímicos dos stocks pesquisados: cinco do SP, nove do SASF e cinco do SFA.

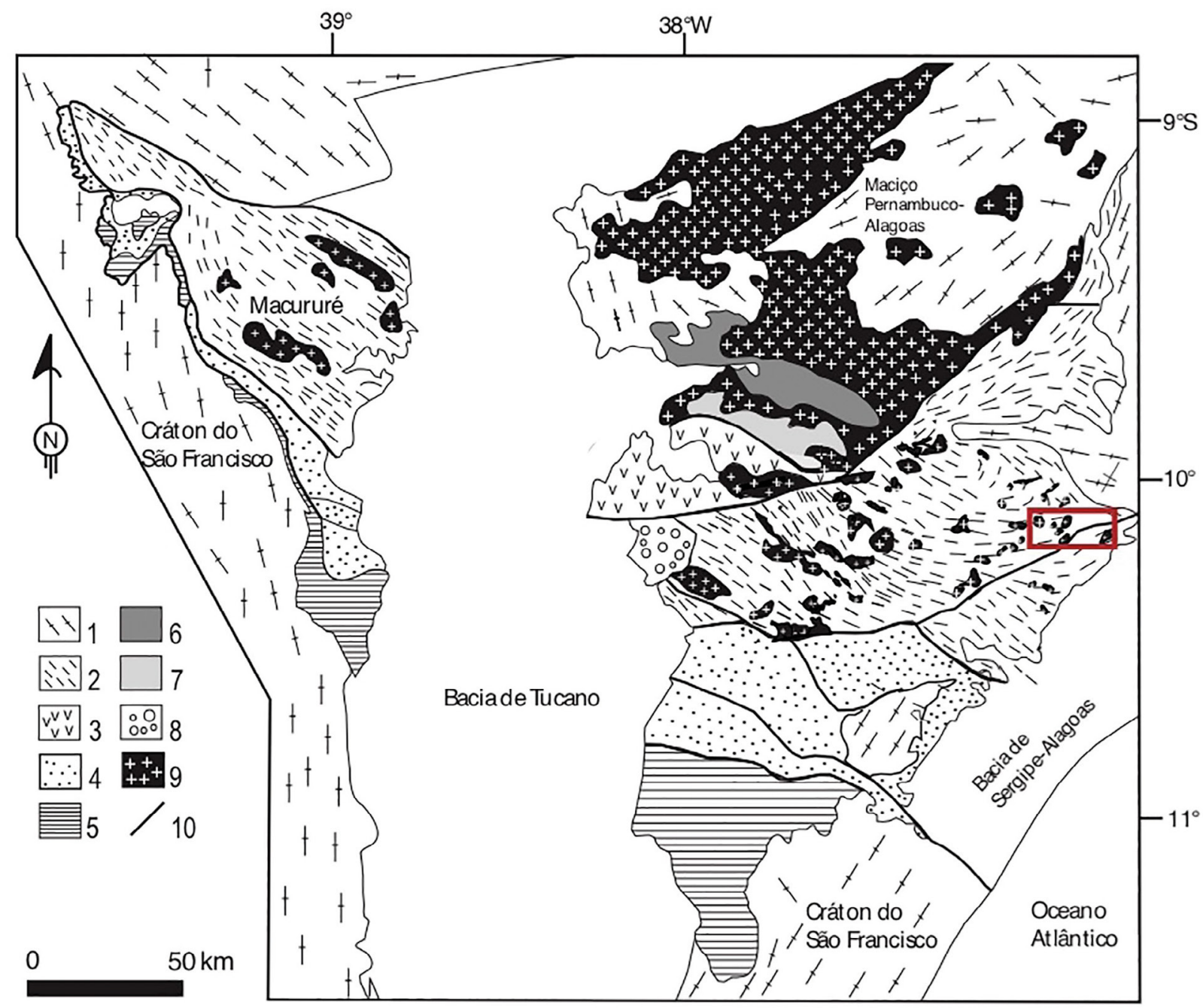

1: Gnaisses de alto grau; 2: Domínio Macururé; 3: Domínio Marancó; 4: Domínio Vaza-Barris; 5: Domínio Estância; 6: Domínio Canindé; 7: Domínio Paço Redondo; 8: Graben Juá; 9: Plútons Brasilianos; 10: Zonas de cisalhamento.

Figura 1. Esquema do Sistema Orogênico Sergipano apresentando os domínios geológicos descritos por Davison e Santos (1989). A área delimitada pelo polígono vermelho corresponde ao mapa apresentado na Figura 2. 
As lâminas delgado-polidas foram confeccionadas no Laboratório de Preparação de Amostras da Superintendência de Salvador do Serviço Geológico do Brasil (Companhia de Pesquisa de Recursos Minerais - CPRM). Essas lâminas foram estudadas inicialmente com o auxílio de microscópio petrográfico-metalográfico e, em seguida, com microscópio eletrônico de varredura (MEV). Esses estudos foram realizados no Condomínio de Laboratórios Multiusuários das Geociências da Universidade Federal de Sergipe (CLGeo-UFS).

A identificação de alguns dos minerais dos pegmatitos presentes nos stocks estudados (e.g. turmalina, magnetita, ilmenita, hematita) foi feita utilizando-se a técnica de difratometria de raios $\mathrm{X}$ (DRX), pelo método do pó. A composição química dos cristais de feldspatos foi obtida utilizando-se espectrômetro de energia dispersiva (EDS) acoplado a MEV. A aferição dos dados obtidos com EDS foi feita utilizando padrões internacionais Artimex ${ }^{\circledast} \mathrm{e} \mathrm{Cameca}^{\circledR}$ de feldspatos (ortoclásio, microclina, albita $\left[\mathrm{An}_{10}\right]$, oligoclásio $\left[\mathrm{An}_{25}\right]$, andesina $\left.\left[\mathrm{An}_{40}\right]\right)$. O EDS permitiu igualmente a identificação de vários minerais acessórios com tamanhos inferiores a $0,1 \mathrm{~mm}$ (thorita, barita, monazita, Ti-magnetita, Ce-bastnaesita, ilmenita). As condições analíticas utilizadas nas dosagens químicas pontuais dos minerais foram $20 \mathrm{kV}$ e $17 \mathrm{nA}$. Imagens de elétrons retroespalhados foram elaboradas para melhor observar feições internas dos cristais, particularmente a zonação em cristais de plagioclásio e de zircão.

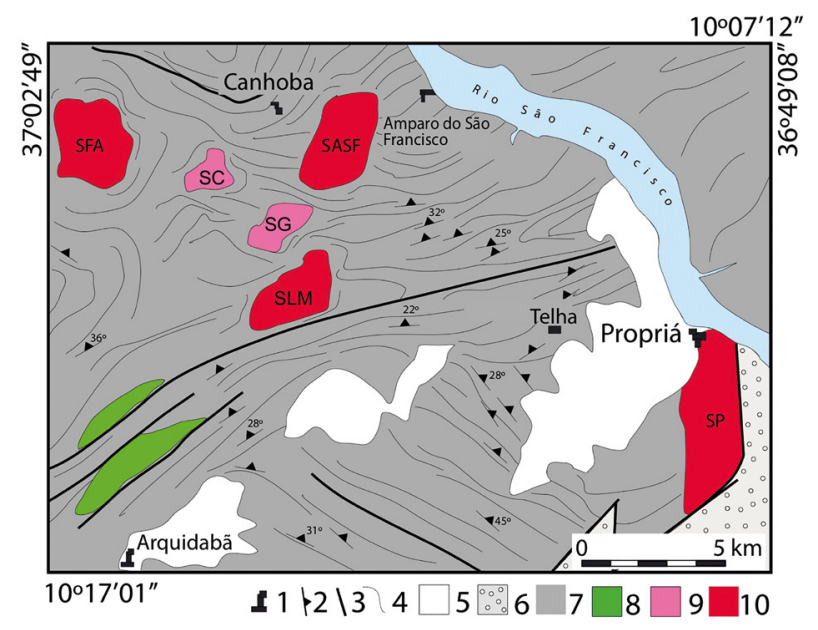

1: Cidades; 2: foliação metamórfica; 3: falha; 4: lineamentos observados em fotografias aéreas; 5: coberturas recentes; 6: rochas sedimentares da sub-bacia de Sergipe; 7: metassedimentos do Domínio Macururé; 8: rochas básicas e ultrabásicas do município de Aquidabã; 9: granitos a duas micas, muscovita e biotita; 10: monzonitos, sienitos e granitos.

Figura 2. Esboço geológico da área em estudo obtido a partir do mapa de Teixeira (2014) acrescido dos lineamentos fotogeológicos. Stocks graníticos: Propriá (SP), Amparo do São Francisco (SASF), Fazenda Alvorada (SFA), Canhoba (SC), Gravata (SG) e Lagoa do Mato (SLM), Canhoba (SC), Gravata (SG) e Lagoa do Mato (SLM).
Cristais de zircão de uma amostra do SP foram separados utilizando-se a metodologia clássica (Gill e Ramsey, 1997): britagem, trituração, moagem e separação eletromagnética - e o material não magnético foi separado por líquidos densos. Os concentrados de cristais de zircão foram montados em resina epoxy, em seguida polidos com pasta de diamante. A montagem foi metalizada com ouro para a observação das estruturas internas dos cristais de zircão utilizando-se da catodoluminescência e elétrons retroespalhados em MEV. As imagens feitas foram analisadas objetivando seleção dos melhores cristais para determinações geocronológicas na Universidade de São Paulo (USP).

As determinações das razões isotópicas foram realizadas no Laboratório de Geocronologia de Alta Resolução do Instituto de Geociências da USP. O equipamento utilizado foi o Sensitive High Resolution Ion Micro-Probe (SHRIMP), modelo IIe/MC. As condições analíticas estão detalhadas em Sato et al. (2014) e os procedimentos são aqueles estabelecidos por Compston et al. (1984) e Williams (1997). $\mathrm{O}$ padrão utilizado para medir as concentrações isotópicas foi o TEMORA $2\left({ }^{206} \mathrm{~Pb} /{ }^{238} \mathrm{U} 416,8 \pm 0,3 \mathrm{Ma}\right)$. Os erros nos índices isotópicos e nas idades são de 1sigma. Os resultados obtidos das análises foram calculados e alocados em diagramas com o auxílio do programa SQUID/Excel macro (Ludwig, 2009).

As análises geoquímicas foram realizadas no Laboratório Acme, Canadá. Os elementos maiores foram dosados por ICP-OES e os elementos-traço, por ICP-MS. As rochas nomeadas com a sigla SOS foram analisadas pela técnica fluorescência de raios $X$ com pó-prensado no Laboratório de Geoquímica do CLGeo-UFS (Pereira, 2017).

$\mathrm{O}$ tratamento dos dados geoquímicos foi feito utilizando-se de planilhas Excel ${ }^{\oplus}$ e do software Geochemical Data Toolkit for Windows (GCDkit), versão 2.3, de Janoušek et al. (2008).

\section{GEOLOGIA DOS STOCKS ESTUDADOS}

O SP, o SASF e o SFA correspondem a intrusões com áreas aflorantes inferiores a $10 \mathrm{~km}^{2}$ que truncam a foliação regional (Propriá e Amparo do São Francisco), e no caso do SFA essa foliação se acomoda ao contorno da intrusão (Figura 2).

\section{Stock Propriá}

Aárea aflorante do SP é de 9,5 $\mathrm{km}^{2}$ (Figura 2). Este corpo tem forma alongada e é intrusivo em metassedimentos e biotita xistos do Domínio Macururé. Bons afloramentos são restritos às pedreiras localizadas ao sudoeste da sede municipal, onde as amostras foram coletadas. Ao leste e ao sul ele faz contatos por falha com os sedimentos da Bacia Sedimentar Sergipe-Alagoas. Ao oeste, o contato é intrusivo com os 
metassedimentos do Domínio Macururé, sendo parcialmente encoberto por sedimentos recentes. A presença de xenólitos de metassedimentos nos granitos e o aumento do tamanho dos cristais de almandina nos biotita xistos encaixantes são interpretados como resultado do aquecimento provocado pela intrusão do SP. Os granitos não apresentam orientação, são porfiríticos e têm matriz de granulação média a grossa (Figura 3A). Os fenocristais de feldspato alcalino são poiquilíticos, zonados e exibem com frequência textura rapakivi (Figura 3B). Enclaves máficos microgranulares mostram-se com formas elipsoides e com tamanhos não superiores a $20 \mathrm{~cm}$ de comprimento (Figura 3C). É frequente a presença de diques pegmatíticos de cor rosa intenso (devido a grande quantidade de cristais de feldspato alcalino), o que contrasta com os cristais anédricos e intersticiais de turmalina de cor preta e de magnetita. Os contatos entre granitos e diques são variáveis, retos a difusos.

\section{Stock Amparo do São Francisco}

O SASF, com $6,5 \mathrm{~km}^{2}$, tem forma arredondada (Figura 2). É constituído por rochas sem orientação preferencial, de coloração cinza, granulação média a grossa e frequentemente porfirítica, com fenocristais de feldspato (Figura 4A). Ele é intrusivo nos metassedimentos do Domínio Macururé dos quais contêm xenólitos de granada biotita xisto $(<40 \mathrm{~cm})$. Os contatos são dificilmente observáveis em campo, todavia em vários perfis efetuados percebe-se a passagem brusca das rochas ígneas para as metamórficas encaixantes. Enclaves máficos microgranulares $(2-1,5 \mathrm{~m})$ com formas variadas são frequentes e ocasionalmente nota-se a presença de enclaves múltiplos (Figura 4B). Os diques do SASF são de composição granítica, com menor granulação que as rochas encaixantes e contatos geralmente retos. Fraturas comumente ocorrem e algumas são preenchidas por quartzo e/ou feldspato potássico.

\section{Stock Fazenda Alvorada}

O SFA tem forma arredondada e área de $6,8 \mathrm{~km}^{2}$ (Figura 2). As rochas que constituem esse stock exibem cor cinza esbranquiçada, têm granulação média a grossa (Figura 5) e exibem a presença ocasional fenocristais. Diferente dos outros dois stocks estudados, o SFA não apresenta enclaves e diques de pegmatito são raros. Fraturas preenchidas por veios de quartzo por vezes foram observadas.

\section{IDADE DO STOCK PROPRIÁ}

Analisou-se a amostra FDS-516A(UTM 7362855S/8867104W), que corresponde a um sienogranito. Doze spots foram analisados neste estudo, dos quais sete deles foram utilizados para o cálculo da idade apresentada (Tabela 1). Estes apresentam razões Th/U variando de 0,06 a 1,75 , com média 0,82 (Tabela 1 ). Os cristais datados são euédricos e bem formados, apresentando zonação oscilatória comum em cristais magmáticos, permitindo inferir que a idade obtida represente a da cristalização magmática. A idade $\mathrm{U}-\mathrm{Pb}_{\text {Shrimp }}$ em zircão de $615 \pm 6$ Ma obtida para o SP é interpretada como a de cristalização (Figura 6).
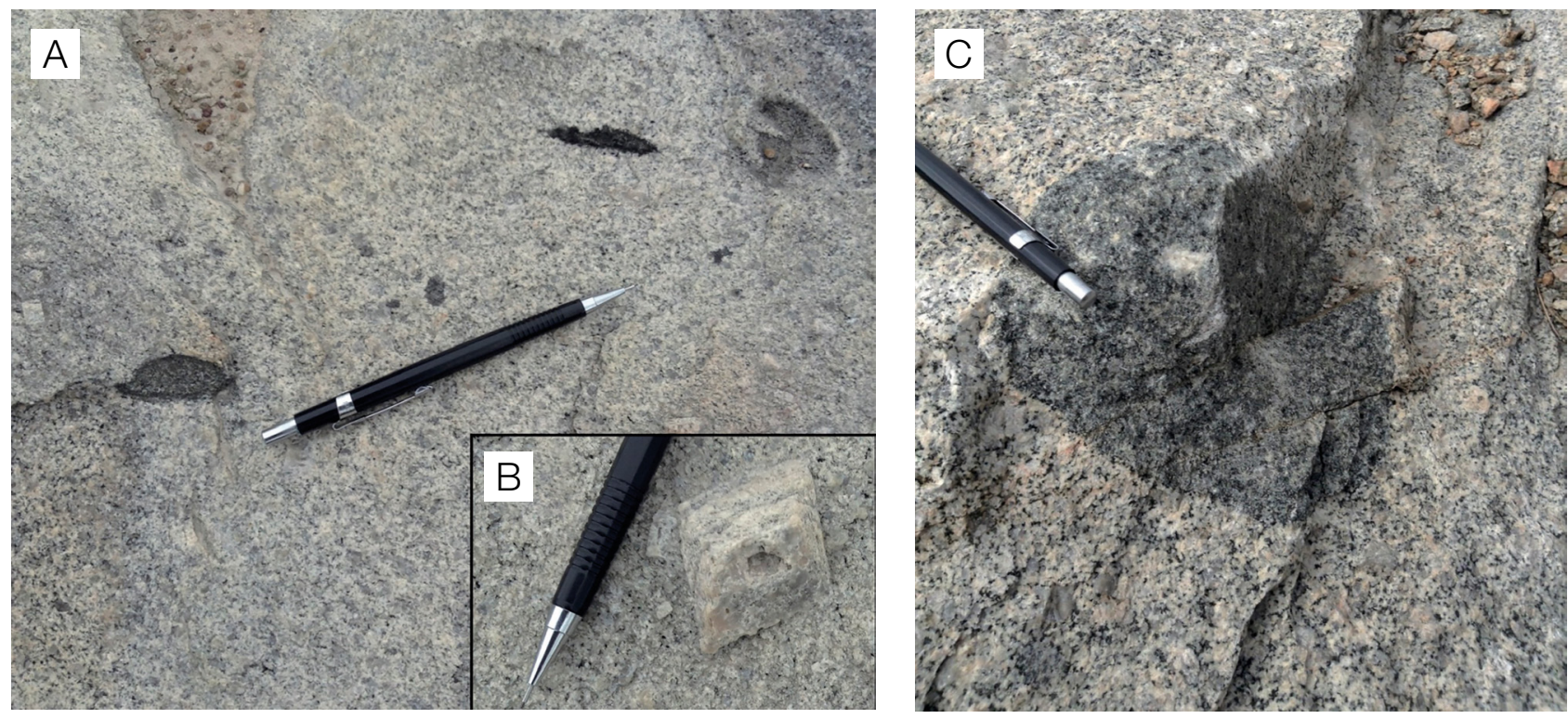

Figura 3. Imagens apresentando texturas em rochas do Stock Propriá. (A) Textura porfirítica com fenocristais de feldspato alcalino de cor branca $(\approx 4 \mathrm{~cm})$ imersos em matriz de granulação média. (B) Detalhe da textura porfirítica com fenocristal euédrico de feldspato alcalino em matriz de granulação média. (C) Enclave máfico microgranular com fenocristais de biotita imerso em matriz mesocrática de granulação fina a média. 
Silva Filho et al. (2016) descrevem nos terrenos do Domínio Pernambuco-Alagoas, situado a norte do SOS, que o magmatismo potássico ocorre em três grupos: primeiro conjunto reúne o magmatismo potássico precoce a sincrônico à colisão, com idade de cristalização em torno de $635 \mathrm{Ma}$ (e.g., Batólito Serra do Catu); o segundo conjunto reúne o magmatismo sincrônico à colisão (e.g., Água Branca), com idades de cristalização variando de 610 a $618 \mathrm{Ma}$; e o terceiro conjunto de corpos correspondendo ao magmatismo pós-colisional, com idade de cristalização de $590 \mathrm{Ma}$ (e.g., Águas Belas).

No Domínio Macururé tem-se plutonismo shoshonítico representado pelo Stock Glória Norte, com idade de cris-

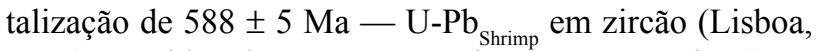
2014), considerado como magmatismo pós-tectônico (pós-orogênico). Essa idade corresponde à do magmatismo considerado por Silva Filho et al. (2016) como pós-colisonal. A idade U-Pb $\mathrm{PHRIMP}_{\text {SH }}$ em zircão de $615 \pm 6 \mathrm{Ma}$ obtida para o SP situa-se no intervalo considerado por Silva Filho et al. (2016) como do magmatismo potássico sincrônico à colisão. Todavia, não foram observadas no SP evidências de importante deformação regional, usualmente presentes em intrusões sincrônicas à deformação.

\section{PETROGRAFIA}

As rochas dos três stocks estudados apresentam textura porfirítica com matriz de granulação média a grossa. Os fenocristais presentes são de feldspato alcalino pertítico, plagioclásio e, ocasionalmente, biotita. Segundo Chayes (1956), quando as rochas apresentam granulação média a grossa e textura porfirítica, uma lâmina não é suficiente para determinar a moda. Outro aspecto é que os feldspatos nessas rochas são pobremente geminados. Ante a essas feições, optou-se por se estabelecer a nomenclatura utilizando-se dados geoquímicos com diagrama Q' versus ANOR (Figura 7), conforme proposto por Streckeisen e Le Maître (1979), que apresenta boa correspondência entre a mineralogia normativa e a nomenclatura com base na moda (QAPF) proposta pelo diagrama Streckeisen (1976).

\section{Stock Propriá}

É constituído de sienogranito e o enclave máfico microgranular corresponde a quartzo sienito (Figura 7). Os sienogranitos porfiríticos são rochas isotrópicas, ocasionalmente com foliação magmática orientando cristais de biotita e fenocristais

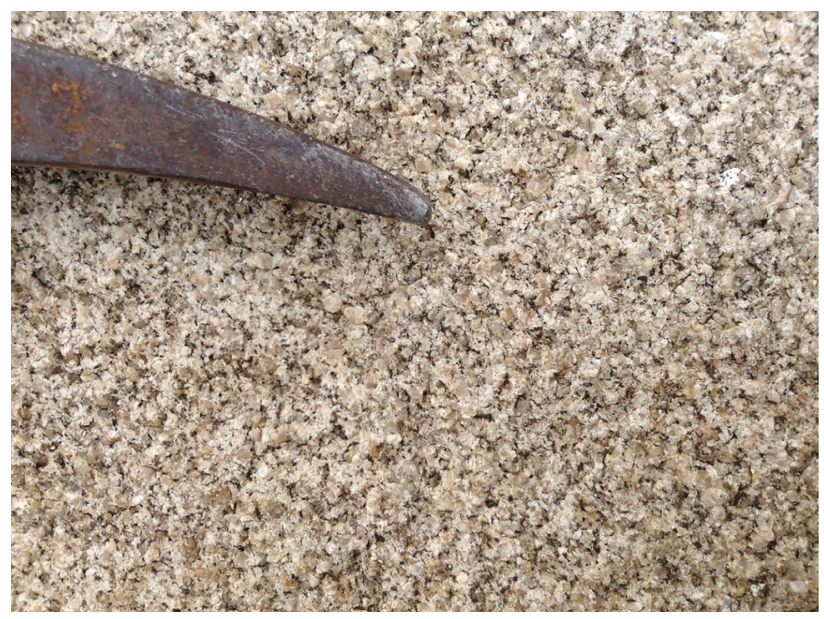

Figura 5. Textura equigranular maciça, característica das rochas do Stock Fazenda Alvorada.

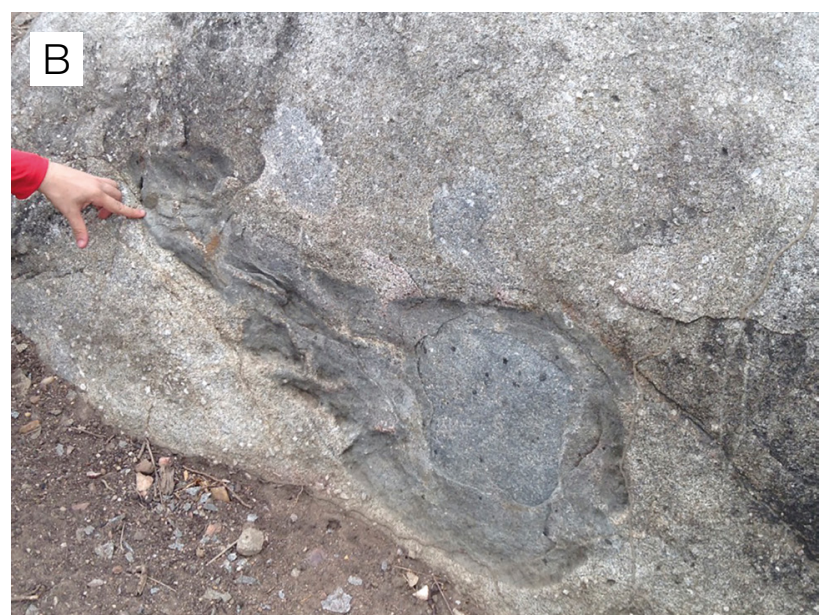

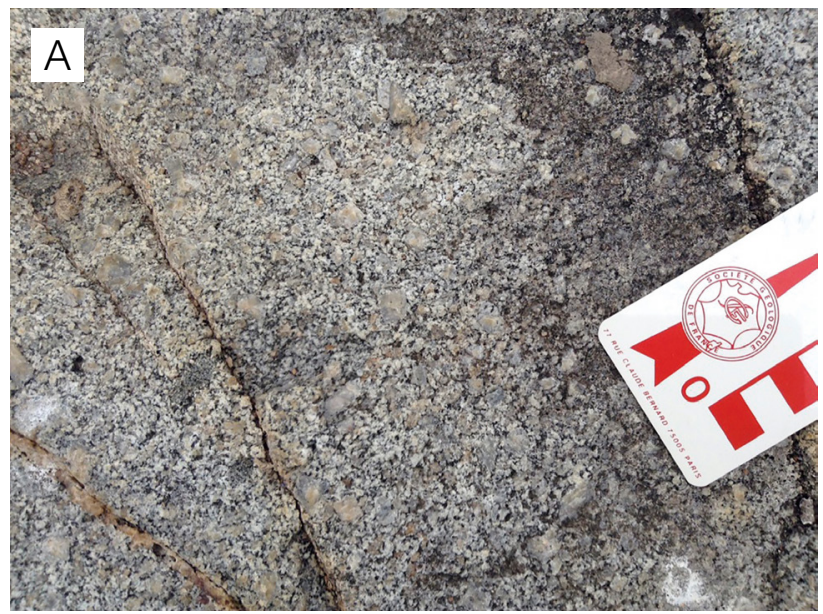

Figura 4. Imagens com texturas do Stock Granítico Amparo do São Francisco. Textura porfirítica com fenocristais de feldspato alcalino de cor clara (até $1,5 \mathrm{~cm}$ ) imersos em matriz de granulação média a grossa. (A) Os pontos pretos correspondem a cristais de biotita. (B) Enclave máfico microgranular apresenta-se alongado segundo a direção da foliação magmática. Notar contatos irregulares e interpenetrantes com o monzonito encaixante. As pontuações de cor preta no enclave correspondem a fenocristais de biotita. 
de feldspatos. Os fenocristais de feldspato alcalino pertítico e plagioclásio chegam a atingir até $4 \mathrm{~cm}$. Esses fenocristais estão imersos em uma matriz fanerítica média a grossa, constituída de biotita, plagioclásio, feldspato alcalino e quartzo. Os minerais acessórios presentes são magnetita, ilmenita, pirita, titanita, epídoto, allanita, monazita, apatita e zircão.

Os cristais de biotita marrom são subédricos a euédricos e têm pleocroísmo variando de verde-escuro, amarelo-claro e marrom-esverdeado. Os tamanhos variam de 0,13 até $1,05 \mathrm{~mm}$, existindo predominância de cristais com tamanho de $0,46 \mathrm{~mm}$. Inclui cristais de zircão, apatita, titanita, epídoto, monazita, thorita e quartzo.

Os fenocristais de oligoclásio $\left(\mathrm{An}_{12-26} ;\right.$ Figura 8$)$, com tamanhos variando de 4 a 1,3 mm são subédricos e apresentam frequentemente zoneamentos múltiplos com contatos ameboides entre as zonas (Figura 9A), sugerindo embaiamento. Os cristais de plagioclásio da matriz correspondem a oligoclásio $\left(\mathrm{An}_{16-18}\right)$, podendo ter periferia com composição de albita $\left(\mathrm{An}_{2-6}\right)$. Eles são subédricos e anédricos e exibem tamanhos variando de 0,4 a 0,8 $\mathrm{mm}$ (Figura 9B). Alguns cristais têm textura mirmequítica. Incluem cristais de titanita, biotita, epídoto, apatita e zircão. Ocorrem alterado para saussurita.

O feldspato alcalino pertítico $\left(\mathrm{Or}_{97-93}\right.$ e $\left.\mathrm{Ab}_{3-7}\right)$ é subédrico. Os fenocristais de ortoclásio apresentam tamanhos em torno de $4 \mathrm{~mm}$, com geminação bem desenvolvida. Os cristais da matriz têm tamanhos que variam de 0,1 até $2 \mathrm{~mm}$, predominando aqueles com $1 \mathrm{~mm}$, e têm geminação albita-periclina, com distribuição irregular nos cristais. Inclui cristais de oligoclásio zonado, biotita, epídoto normalmente em agregados, e cristais de apatita, monazita e zircão distribuídos aleatoriamente.

O quartzo é anédrico, com tamanhos variando de 0,13 até $2,6 \mathrm{~mm}$, sendo o tamanho médio dos cristais da matriz de $0,78 \mathrm{~mm}$. Inclui cristais de zircão subédrico e zonado, titanita, biotita, feldspato alcalino e epídoto subédricos.

A titanita marrom euédrica apresenta granulação variando de 0,13 a 1,05 mm, com predomínio de cristais com 0,19 mm. É frequente bordejar cristais de ilmenita e Ti-magnetita, indicando cristalização tardia.

Os cristais de epídoto são desde euédricos a anédricos. Ocorrem com tamanhos variando de 0,02 até $0,65 \mathrm{~mm}$, com dominância dos cristais com 0,20 mm. Apresentam-se como dois tipos texturais distintos: o epídoto euédrico, interpretado como magmático, apresenta os tamanhos maiores $(0,25$ a

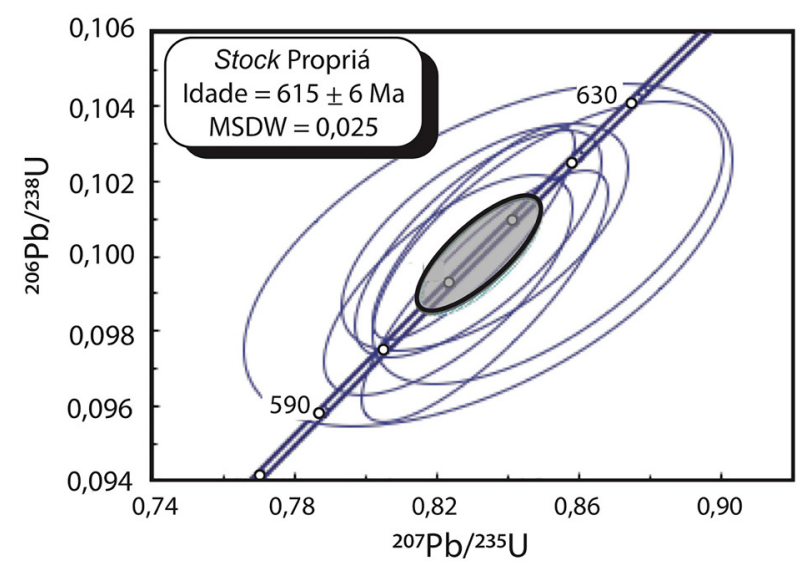

Figura 6. Concórdia U-Pb para os cristais de zircão da amostra FDS-516A.

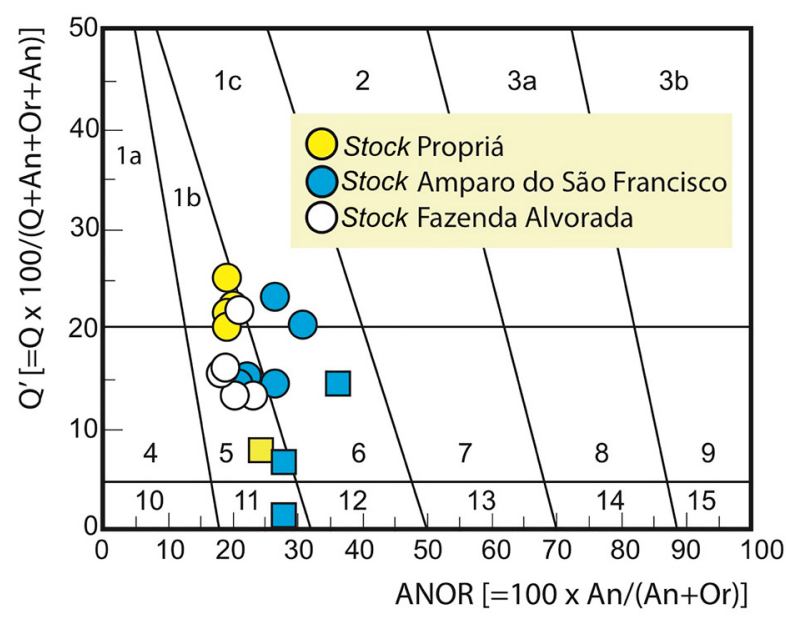

1A: Granito alcalino; 1B: sienogranito; 1C: monzogranito; 3A: tonalito; 3B: tonalito cálcico; 4: quartzo sienito alcalino; 5: quartzo sienito; 6: quartzo monzonito; 7: quartzo monzodiorito; 8: quartzo diorito; 9: quartzo gabro; 10: sienito alcalino; 11: sienito; 12: monzonito; 13: monzogabro; 14: diorito; 15: gabro.

Figura 7. Diagrama Q' versus ANOR de Streckeisen e Le Maître (1979) aplicado às rochas estudadas. Rochas dominantes (circulo) e os enclaves (quadrado).

Tabela 1. Dados de U-Pb ${ }_{\text {SHRIMP }}$ obtidos para cristais de zircão do Stock Propriá.

\begin{tabular}{|c|c|c|c|c|c|c|c|c|c|c|c|}
\hline \multirow{2}{*}{ Spot } & \multirow{2}{*}{$\begin{array}{c}\mathrm{U} \\
\text { (ppm) }\end{array}$} & \multirow{2}{*}{$\begin{array}{c}\text { Th } \\
(p p m)\end{array}$} & \multirow{2}{*}{$\mathrm{Th} / \mathrm{U}$} & \multicolumn{6}{|c|}{ Razões isotópicas } & \multirow{2}{*}{$\begin{array}{c}\text { Idade }(\mathrm{Ma})-2 \delta \\
{ }^{206} \mathrm{~Pb} /{ }^{238} \mathrm{U}\end{array}$} & \multirow{2}{*}{$\begin{array}{c}\text { Discordância } \\
(\%)\end{array}$} \\
\hline & & & & ${ }^{207} \mathrm{~Pb} /{ }^{206} \mathrm{~Pb}$ & $\pm \%$ & ${ }^{207} \mathrm{~Pb} /{ }^{235} \mathrm{U}$ & $\pm \%$ & ${ }^{206} \mathrm{~Pb} /{ }^{238} \mathrm{U}$ & $\pm \%$ & & \\
\hline 1.1 & 618 & 338 & 0,55 & 0,0599 & 0,8 & 0,831 & 1,4 & 0,1006 & 1,2 & $618 \pm 7$ & -3 \\
\hline 2.1 & 319 & 144 & 0,45 & 0,0615 & 1,8 & 0,851 & 2,4 & 0,1003 & 1,5 & $618 \pm 10$ & +7 \\
\hline 4.1 & 443 & 776 & 1,75 & 0,0611 & 1,0 & 0,833 & 1,7 & 0,0989 & 1,4 & $613 \pm 11$ & +6 \\
\hline 5.1 & 296 & 388 & 1,31 & 0,0601 & 1,2 & 0,832 & 1,7 & 0,1003 & 1,2 & $619 \pm 9$ & -1 \\
\hline 6.1 & 100 & 71 & 0,71 & 0,0605 & 2,8 & 0,834 & 3,4 & 0,1000 & 1,9 & $617 \pm 12$ & +1 \\
\hline 7.1 & 363 & 24 & 0,06 & 0,0602 & 1,2 & 0,823 & 1,7 & 0,0992 & 1,2 & $610 \pm 7$ & +0 \\
\hline 8.1 & 234 & 204 & 0,87 & 0,0601 & 1,6 & 0,834 & 2,0 & 0,1005 & 1,2 & $620 \pm 8$ & -1 \\
\hline
\end{tabular}


$0,65 \mathrm{~mm}$ ); já o epídoto anédrico ocorre em agregados, seus tamanhos são inferiores a $0,25 \mathrm{~mm}$, mostra-se associado a mica branca, exibe inclusões vermiculares de quartzo e foi interpretado como resultado da alteração do plagioclásio. Cristais de bastnaesita e barita ocorrem associados à alteração dos cristais de epídoto.

O enclave máfico microgranular corresponde a quartzo sienito, exibe cor cinza a preta (Figura 3C) e é isotrópico. Ele tem a mesma mineralogia e textura dos sienogranitos encaixantes. Todavia, diferencia-se deles pela abundância de cristais aciculares de apatita e biotita, sugerindo maior velocidade de resfriamento.

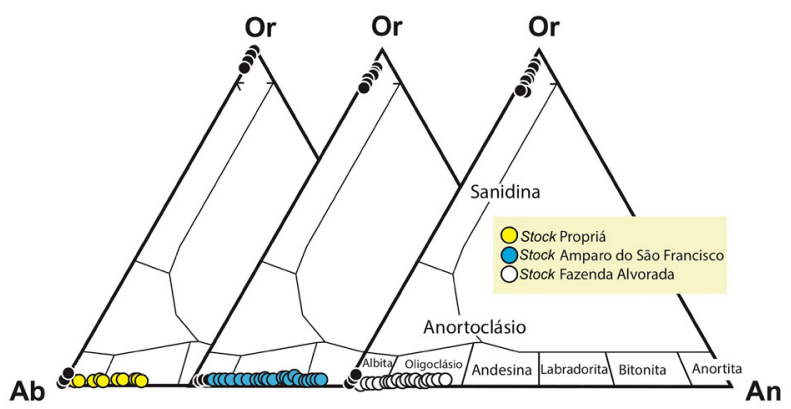

Figura 8. Diagramas Albita (Ab) - Ortoclásio (Or) - Anortita (An) apresentando as composições dos feldspatos nos stocks estudados. Os círculos coloridos referem-se aos cristais de plagioclásio e os pretos aos de feldspato alcalino pertítico.

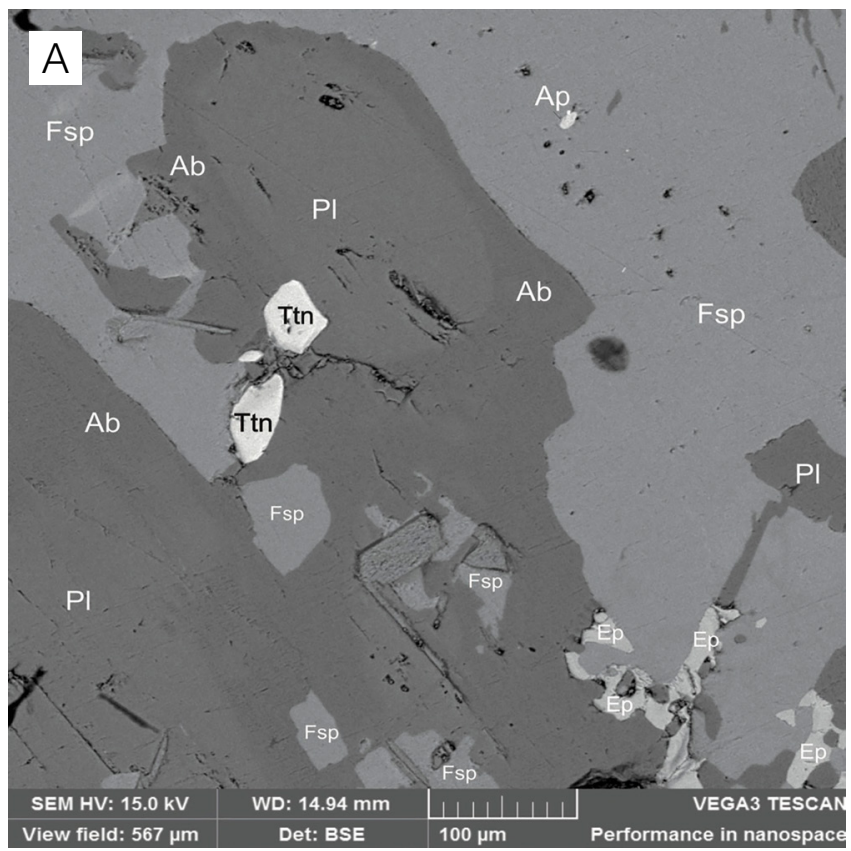

\section{Stock Amparo do São Francisco}

Este stock é constituído de monzogranitos, quartzo monzonitos e quartzo sienitos. Os enclaves microgranulares correspondem a quartzo monzonito, quartzo sienito e sienito (Figura 7).

Os monzogranitos e quartzo sienitos apresentam cor cinza esbranquiçada, textura porfirítica em matriz de granulometria média a grossa. A mineralogia é formada por feldspato alcalino pertítico, plagioclásio, biotita, quartzo, titanita e epídoto.

Os fenocristais de feldspato alcalino pertítico $\left(\mathrm{Or}_{89}\right.$ $\left.{ }_{97} \mathrm{e} \mathrm{Ab}_{11-3}\right)$ são subédricos e suas dimensões variam de 4 a 2,8 mm. Exibem geminação Carlsbad, tendo a AlbitaPericlina sobreposta. Os cristais da matriz têm tamanho médio de $0,7 \mathrm{~mm}$ e limitam-se a apresentar geminação Albita-Periclina. Identificaram-se inclusões de biotita, titanita, apatita, zircão, epídoto e ilmenita.

Os fenocristais de plagioclásio $\left(\mathrm{An}_{20-35} ;\right.$ Figura 8$)$ têm granulação variando de 1,2 até $3 \mathrm{~mm}$, exibem zoneamento composicional múltiplo (normal e oscilatório) e incluem cristais de minerais opacos, zircão e apatita acicular. Os cristais da matriz correspondem a oligoclásio $\left(\mathrm{An}_{12-28}\right)$, têm tamanhos variando de 0,8 até $0,4 \mathrm{~mm}$ e incluem cristais de biotita, zircão, epídoto, titanita, apatita acicular e quartzo. Alguns dos cristais apresentam-se parcialmente saussuritizados.

A biotita é marrom, os tamanhos variam de 1 a $0,1 \mathrm{~mm}$, e ocasionalmente ocorre orientada pelo fluxo magmático.

PI: plagioclásio; Biot: biotita; Ab: albita; Tnt: titanita; Fsp: feldspato alcalino; Qz: quartzo.

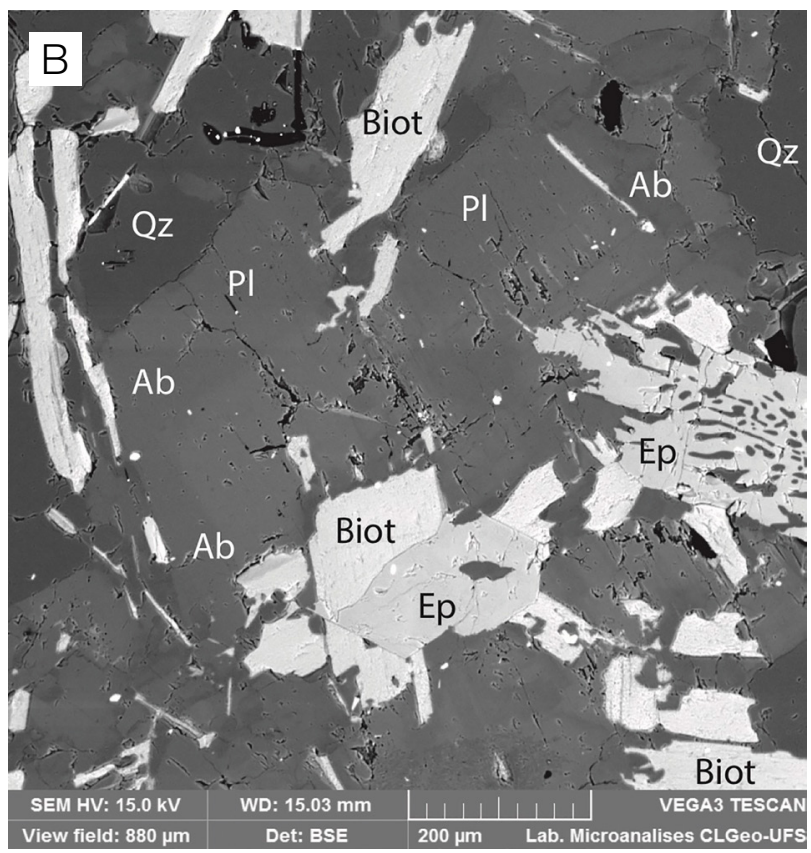

Figura 9. (A) Imagens de elétrons retroespalhados de texturas dos stocks Propriá e (B) Amparo do São Francisco onde se tem zonação composicional em cristais de plagioclásio (cor cinza mais claro plagioclásio mais rico em cálcio e cinza mais escuro plagioclásio rico em sódio). Notar os (A) contatos curvos e (B) embainhados. 
Inclui cristais de zircão, apatita subédrica no centro dos cristais. Nas bordas são verificadas inclusões de titanita subédrica e euédrica, epídoto e monazita subédrica. Altera-se ocasionalmente para clorita e com barita em planos de clivagem.

O quartzo é anédrico, com tamanhos variando de 0,1 a $1,1 \mathrm{~mm}$, com tamanho médio de $0,7 \mathrm{~mm}$. Inclui cristais de zircão, apatita, titanita e biotita. A titanita é euédrica e subédrica, tem tamanho variando de 0,1 a $0,8 \mathrm{~mm}$, limitando-se a ocorrer na matriz, e é associada a minerais opacos. Os cristais de epídoto são euédricos e anédricos. Estes últimos frequentemente ocorrem reunidos em agregados e estão associados aos cristais de biotita. Exibem tamanhos variando de 1,1 até $0,20 \mathrm{~mm}$, com predomínio de $0,4 \mathrm{~mm}$. Cristais de zircão e apatita são usualmente euédricos.

Os enclaves têm mineralogia principal composta por biotita, anfibólio, quartzo, plagioclásio e feldspato alcalino. Os acessórios são apatita, barita, clorita, epídoto, magnetita, ilmenita, pirita, muscovita, titanita e zircão. A barita e a pirita tendem a ocorrer em fraturas e nas clivagens da biotita, indicando tratar-se de fases hidrotermais tardias.

\section{Stock Fazenda Alvorada}

Este stock é constituído por sienogranitos e quartzo sienitos de coloração clara. Essas rochas apresentam estrutura isotrópica, textura porfirítica e granulação média a grossa da matriz. Os minerais essenciais são plagioclásio, feldspato alcalino, quartzo, biotita, epídoto e titanita. Os acessórios são zircão, titanita, apatita, ilmenita e epídoto.

Os cristais de oligoclásio $\left(\mathrm{An}_{11-25}\right)$ presentes nessas rochas (Figura 8) apesentam tamanhos que variam de 0,8 a $0,6 \mathrm{~mm}$ e ocorrem geminados segundo as leis Albita e Albita-Carlsbad. Os fenocristais mostram-se, por vezes, zonados. Apresentam inclusões de: biotita, titanita, apatita, zircão, epídoto e quartzo.

$\mathrm{O}$ feldspato alcalino pertítico $\left(\mathrm{Or}_{87-98} \mathrm{e} \mathrm{Ab}_{13-2}\right)$ subédrico a euédrico ocorre tanto na matriz quanto como nos fenocristais. Os tamanhos variam de 4,8 a $3 \mathrm{~mm}$ para os fenocristais e em torno de $0,4 \mathrm{~mm}$ na matriz. As geminações são Albita-Periclina e Carlsbad. Inclui cristais de biotita, titanita, apatita, plagioclásio, epídoto.

Os cristais de quartzo são anédricos e os tamanhos variam de 2,4 a 0,3 $\mathrm{mm}$, predominando aqueles com $1,1 \mathrm{~mm}$. Incluem cristais de titanita, apatita e biotita.

A biotita é marrom e subédrica, com tamanhos variando de 0,8 a $0,1 \mathrm{~mm}$, predominando $0,6 \mathrm{~mm}$. Inclui cristais de: titanita, epídoto, zircão e apatita. Alguns raros cristais de biotita encontram-se alterados para clorita.

Os cristais de epídoto com maior dimensão $(0,5$ a $0,7 \mathrm{~mm})$ são subédricos e euédricos. Os cristais com menor tamanho $(<0,2 \mathrm{~mm})$ ocorrem anédricos e formam aglomerados. Observaram-se inclusões de titanita nos cristais maiores, assim como intercrescimento mirmequítico do quartzo no epídoto.
A titanita ocorre anédrica a euédrica e com tamanho médio de $0,4 \mathrm{~mm}(0,6$ a $0,1 \mathrm{~mm})$. Ela coroa usualmente os minerais opacos.

\section{GEOQUÍMICA}

Dezenove amostras representativas dos três stocks estudados foram selecionadas para análises químicas para elementos maiores, menores (Tabela 2). Estas foram: cinco do SP, uma das quais é enclave (FDS-516D1); nove do SASF, sendo três delas enclaves (GeSe-399A, SOS-681B, SOS-683B); e cinco do SFA. Desse conjunto, seis rochas foram analisadas para elementos-traço (Tabela 3).

As rochas que constituem os stocks apresentam pequena variação para $\mathrm{SiO}_{2}(62,54$ a $69,9 \%)$ e $\mathrm{Al}_{2} \mathrm{O}_{3}(15,19$ a $16,79 \%)$. Os outros óxidos exibem maior variação nos valores: $\mathrm{TiO}_{2}$ (0,35 a $0,81 \%), \mathrm{Fe}_{2} \mathrm{O}_{3}(2,46$ a $5,40 \%), \mathrm{MnO}(0,02$ a $0,06 \%)$, $\mathrm{MgO}\left(0,68\right.$ a 2,10\%), $\mathrm{CaO}$ (1,96 a 3,73\%), $\mathrm{Na}_{2} \mathrm{O}(3,56$ a $4,77 \%) ; \mathrm{K}_{2} \mathrm{O}(3,87$ a $5,91 \%)$ e $\mathrm{P}_{2} \mathrm{O}_{5}(0,14$ a $0,46 \%)$. Os enclaves são as rochas com conteúdos mais baixos de $\mathrm{SiO}_{2}(55$ a $59 \%)$ e $\mathrm{K}_{2} \mathrm{O}(2,78$ a $3,97 \%)$ e apresentam pouca variação em $\mathrm{Al}_{2} \mathrm{O}_{3}(15,01$ a $16,75 \%)$ e $\mathrm{Na}_{2} \mathrm{O}(3,56$ a $5,11 \%)$, com os maiores conteúdos de: $\mathrm{TiO}_{2}$ (até $1,19 \%$ ), $\mathrm{Fe}_{2} \mathrm{O}_{3}$ (até 7,46\%), $\mathrm{MnO}$ (até $0,11 \%$ ), $\mathrm{MgO}$ (até 4,09\%), $\mathrm{CaO}$ (até 5,16\%) e $\mathrm{P}_{2} \mathrm{O}_{5}$ (até $0,56 \%$ ). Essas diferenças refletem graus distintos de fracionamento, em que os enclaves representam os termos menos diferenciados e os granitos do SP correspondem aos tipos mais diferenciados.

Em diagramas $\mathrm{SiO}_{2}$-óxidos o conjunto das amostras dos três stocks mostra bom alinhamento (Figura 10), apresentando correlação negativa entre $\mathrm{SiO}_{2} \mathrm{e} \mathrm{TiO}_{2}, \mathrm{P}_{2} \mathrm{O}_{5}, \mathrm{CaO}$, $\mathrm{Fe}_{2} \mathrm{O}_{3}, \mathrm{CaO}, \mathrm{MnO}$ e $\mathrm{MgO}$. O bom alinhamento presente nesses diagramas para a maioria dos óxidos é interpretado como resultado da cogeneticidade entre os magmas. Todavia, não são evidentes as correlações entre $\mathrm{SiO}_{2}$ com $\mathrm{K}_{2} \mathrm{O}, \mathrm{Na}_{2} \mathrm{O}$ e $\mathrm{Al}_{2} \mathrm{O}_{3}$, o que sugere que a cristalização dos feldspatos é complexa nesses corpos. No SASF e no SFA, o $\mathrm{Na}_{2} \mathrm{O}$ apresenta correlação positiva que pode indicar que a cristalização de plagioclásio mais sódico é tardia. Com o aumento do silício, percebe-se que a razão $\mathrm{K}_{2} \mathrm{O} / \mathrm{Na}_{2} \mathrm{O}$ decresce tanto nos enclaves quanto nas rochas dos stocks, indicando consumo maior de $\mathrm{K}_{2} \mathrm{O}$ durante a evolução, o que pode refletir o fracionamento e o combinado de biotita e feldspato alcalino.

As amostras estudadas posicionam-se no diagrama TAS nos campos das suítes alcalinas e subalcalinas, sempre próximo ao limite (Figura 11A). Elas são potássicas com $\mathrm{K}_{2} \mathrm{O}$ até $5,9 \%$ e apresentam razão $\mathrm{K}_{2} \mathrm{O} / \mathrm{Na}_{2} \mathrm{O}$ variando de $0,5 \mathrm{a}$ 1,5 (Figura 10). As rochas do SP mostram afinidade com as suítes cálcio-alcalinas de alto $\mathrm{K}_{2} \mathrm{O}$ (Figura 11B) e as rochas do SASF e SFA posicionam-se no campo das suítes shoshoníticas (Figura 11B). No diagrama $\mathrm{SiO}_{2}$ versus 
Tabela 2. Análises químicas dos elementos maiores e minerais normas CIPW dos stocks estudados; perda ao fogo é LOI. As amostras com asteriscos correspondem a enclaves.

\begin{tabular}{|c|c|c|c|c|c|c|c|c|c|}
\hline & \multicolumn{9}{|c|}{ Stock Propriá } \\
\hline & \multicolumn{2}{|c|}{ FDS-516D1* } & \multicolumn{2}{|l|}{ FDS-516B } & \multicolumn{2}{|c|}{ FDS-516A } & FDS-516F & \multicolumn{2}{|c|}{ GeSe522A } \\
\hline $\mathrm{SiO}_{2}$ & \multicolumn{2}{|c|}{59,53} & \multicolumn{2}{|l|}{68,40} & \multicolumn{2}{|l|}{68,59} & 68,66 & \multicolumn{2}{|c|}{69,90} \\
\hline $\mathrm{TiO}_{2}$ & \multicolumn{2}{|c|}{0,85} & \multicolumn{2}{|l|}{0,42} & \multicolumn{2}{|l|}{0,27} & 0,45 & \multicolumn{2}{|c|}{0,42} \\
\hline $\mathrm{Al}_{2} \mathrm{O}_{3}$ & \multicolumn{2}{|c|}{16,75} & \multicolumn{2}{|l|}{16,07} & 15,97 & & 15,53 & \multicolumn{2}{|c|}{15,19} \\
\hline $\mathrm{Fe}_{2} \mathrm{O}_{3}$ & 7,4 & & 2,83 & & 2,62 & & 2,78 & & 2,46 \\
\hline $\mathrm{MnO}$ & 0,1 & & 0,04 & & 0,03 & & 0,03 & & ,03 \\
\hline $\mathrm{MgO}$ & $2,7 C$ & & 0,78 & & 0,75 & & 0,81 & & 0,71 \\
\hline $\mathrm{CaO}$ & $3,1 !$ & & 2,12 & & 2,33 & & 2,21 & & 1,96 \\
\hline $\mathrm{Na}_{2} \mathrm{O}$ & 5,1 & & 4,77 & & 5,32 & & 4,65 & & 4,45 \\
\hline $\mathrm{K}_{2} \mathrm{O}$ & 2,88 & & 3,98 & & 2,76 & & 3,89 & & 3,97 \\
\hline $\mathrm{P}_{2} \mathrm{O}_{5}$ & 0,3 & & 0,14 & & 0,14 & & 0,15 & & 0,16 \\
\hline LOI & 0,9 & & 0,20 & & 0,90 & & 0,60 & & 0,50 \\
\hline Total & 99,7 & & 99,75 & & 99,68 & & 99,76 & & 9,75 \\
\hline Qz & 6,4 & & 19,2 & & 18,9 & & 20,4 & & 23,3 \\
\hline $\mathrm{Pl}$ & 56,8 & & 50,0 & & 55,2 & & 49,2 & & 46,4 \\
\hline Or & 17, & & 23,5 & & 18,9 & & 23,0 & & 23,5 \\
\hline Co & 0,3 & & 0,4 & & 0,0 & & 0,0 & & 0,4 \\
\hline Diop & 0,0 & & 0,0 & & 0,3 & & 0,0 & & 0,0 \\
\hline Hip & 12, & & 3,9 & & 3,7 & & 3,9 & & 3,4 \\
\hline$\| \mathrm{m}$ & 1,6 & 6 & 0,8 & & 0,5 & & 0,9 & & 0,8 \\
\hline Mt & 3,2 & & 1,2 & & 1,2 & & 1,2 & & 1,1 \\
\hline$A p$ & 0,7 & & 0,3 & & 0,3 & & 0,4 & & 0,4 \\
\hline Total & 98, & & 99,4 & & 99,0 & & 98,8 & & 99,2 \\
\hline Albita & 43, & & 40,4 & & 45 & & 39,3 & & 37,7 \\
\hline Anortita & 13,4 & & 9,6 & & 10,2 & & 9,9 & & 8,7 \\
\hline & & & & Stock Amp & aro do São & Francisco & & & \\
\hline & SOS-681B $^{*}$ & SOS-683B & GeSe399B $^{\star}$ & SOS-681A & SOS-676 & SOS-683A & A GeSe399A & SOS-678 & GeSe400 \\
\hline $\mathrm{SiO}_{2}$ & 54,98 & 58,17 & 59,70 & 62,33 & 64,06 & 64,29 & 64,73 & 65,42 & 67,31 \\
\hline $\mathrm{TiO}_{2}^{2}$ & 1,19 & 0,73 & 0,98 & 0,69 & 0,61 & 0,56 & 0,81 & 0,35 & 0,60 \\
\hline $\mathrm{Al}_{2} \mathrm{O}_{3}$ & 15,01 & 15,98 & 15,15 & 15,40 & 15,42 & 15,68 & 15,43 & 15,83 & 15,32 \\
\hline $\mathrm{Fe}_{2} \mathrm{O}_{3}$ & 11,17 & 7,46 & 7,05 & 5,40 & 4,23 & 4,06 & 4,80 & 3,10 & 3,62 \\
\hline $\mathrm{MnO}^{2}$ & 0,11 & 0,09 & 0,11 & 0,06 & 0,05 & 0,04 & 0,06 & 0,04 & 0,05 \\
\hline $\mathrm{MgO}$ & 4,09 & 3,44 & 3,64 & 2,10 & 1,27 & 1,25 & 1,64 & 0,68 & 1,16 \\
\hline $\mathrm{CaO}$ & 4,80 & 4,51 & 5,16 & 3,73 & 3,11 & 2,80 & 3,46 & 2,33 & 2,65 \\
\hline $\mathrm{Na}_{2} \mathrm{O}$ & 3,77 & 3,92 & 3,56 & 3,85 & 3,88 & 4,32 & 3,74 & 3,92 & 3,91 \\
\hline $\mathrm{K}_{2} \mathrm{O}$ & 3,97 & 3,90 & 2,93 & 4,43 & 5,20 & 4,75 & 3,87 & 5,91 & 4,04 \\
\hline $\mathrm{P}_{2} \mathrm{O}_{5}$ & 0,78 & 0,56 & 0,28 & 0,46 & 0,36 & 0,33 & 0,28 & 0,25 & 0,22 \\
\hline LOI & 0,98 & 0,94 & 1,20 & 0,62 & 0,44 & 0,77 & 1,20 & 0,46 & 0,80 \\
\hline Total & 100,85 & 99,70 & 99,76 & 99,07 & 98,63 & 98,85 & 100,02 & 98,29 & 99,68 \\
\hline Qz & 1,2 & 5,5 & 11,3 & 12,2 & 13,5 & 13,3 & 18,0 & 14,0 & 21,2 \\
\hline $\mathrm{Pl}$ & 44,2 & 47,7 & 46,8 & 44,3 & 42,1 & 46,0 & 46,8 & 41,3 & 44,7 \\
\hline Or & 23,5 & 23,1 & 17,3 & 26,2 & 30,7 & 28,1 & 22,9 & 34,9 & 23,9 \\
\hline Co & 0,0 & 0,0 & 0,0 & 0,0 & 0,0 & 0,0 & 0,0 & 0,0 & 0,2 \\
\hline Diop & 5,3 & 3,5 & 5,7 & 3,2 & 3,1 & 2,0 & 1,2 & 1,5 & 0,0 \\
\hline Hip & 16,0 & 12,6 & 11,3 & 7,6 & 4,5 & 5,0 & 6,6 & 3,3 & 5,3 \\
\hline$\| m$ & 2,3 & 1,4 & 1,9 & 1,3 & 1,2 & 1,1 & 1,5 & 0,7 & 1,1 \\
\hline Mt & 4,9 & 3,3 & 3,1 & 2,4 & 1,8 & 1,8 & 2,1 & 1,4 & 1,6 \\
\hline Ap & 1,8 & 1,3 & 0,7 & 1,1 & 0,8 & 0,8 & 0,7 & 0,6 & 0,5 \\
\hline Total & 99,1 & 98,3 & 98,1 & 98,1 & 97,9 & 97,9 & 99,8 & 97,6 & 98,5 \\
\hline
\end{tabular}


Tabela 2. Continuação.

\begin{tabular}{|c|c|c|c|c|c|c|c|c|}
\hline & \multicolumn{8}{|c|}{ Stock Amparo do São Francisco } \\
\hline & SOS-681B* SOS-683B* & GeSe399B* $^{\star}$ & SOS-681A & SOS-676 & SOS-683A & GeSe399A & SOS-678 & GeSe400 \\
\hline Albita & $\begin{array}{ll}31,9 & 33,2\end{array}$ & 30,1 & 32,6 & 32,8 & 36,6 & 30,1 & 33,2 & 33 \\
\hline \multirow[t]{3}{*}{ Anortita } & 12,3 & 16,7 & 11,7 & 9,3 & 9,4 & 16,7 & 8,1 & 11,7 \\
\hline & \multicolumn{8}{|c|}{ Stock Fazenda Alvorada } \\
\hline & SOS-694 & SOS-692 & & SOS-691 & & SOS-693 & & Se598 \\
\hline $\mathrm{SiO}_{2}$ & 62,54 & 63,41 & & 65,42 & & 65,54 & & 8,15 \\
\hline $\mathrm{TiO}_{2}$ & 0,69 & 0,67 & & 0,48 & & 0,46 & & 0,50 \\
\hline $\mathrm{Al}_{2} \mathrm{O}_{3}$ & 16,79 & 16,54 & & 16,15 & & 15,81 & & 6,10 \\
\hline $\mathrm{Fe}_{2} \mathrm{O}_{3}$ & 4,11 & 3,75 & & 3,03 & & 3,07 & & 3,04 \\
\hline $\mathrm{MnO}$ & 0,06 & 0,03 & & 0,02 & & 0,03 & & 0,04 \\
\hline $\mathrm{MgO}$ & 1,58 & 1,23 & & 0,88 & & 0,81 & & 0,69 \\
\hline $\mathrm{CaO}$ & 2,66 & 2,22 & & 2,08 & & 2,33 & & 2,20 \\
\hline $\mathrm{Na}_{2} \mathrm{O}$ & 4,16 & 4,24 & & 4,44 & & 4,47 & & 4,44 \\
\hline $\mathrm{K}_{2} \mathrm{O}$ & 4,79 & 5,34 & & 4,93 & & 5,00 & & 4,24 \\
\hline $\mathrm{P}_{2} \mathrm{O}_{5}$ & 0,39 & 0,33 & & 0,29 & & 0,30 & & 0,16 \\
\hline LOI & 0,83 & 0,68 & & 0,86 & & 0,74 & & 0,42 \\
\hline Total & 97,77 & 97,76 & & 97,72 & & 97,82 & & 9,56 \\
\hline Qz & 11,8 & 11,6 & & 14,9 & & 14,4 & & 19,9 \\
\hline $\mathrm{PI}$ & 45,8 & 44,8 & & 46,0 & & 46,1 & & 47,5 \\
\hline Or & 28,3 & 31,6 & & 29,1 & & 29,6 & & 25,1 \\
\hline Co & 0,9 & 0,5 & & 0,4 & & 0,0 & & 0,6 \\
\hline Diop & 0,0 & 0,0 & & 0,0 & & 1,1 & & 0,0 \\
\hline Hip & 6,7 & 5,4 & & 4,2 & & 3,6 & & 3,7 \\
\hline IIm & 1,3 & 1,3 & & 0,9 & & 0,9 & & 1,0 \\
\hline Mt & 1,8 & 1,6 & & 1,3 & & 1,3 & & 1,3 \\
\hline Ap & 0,9 & 0,8 & & 0,7 & & 0,7 & & 0,4 \\
\hline Total & 97,4 & 97,6 & & 97,5 & & 97,6 & & 99,4 \\
\hline Albita & 35,2 & 35,9 & & 37,6 & & 37,8 & & 37,6 \\
\hline Anortita & 10,6 & 8,9 & & 8,4 & & 8,3 & & 9,9 \\
\hline
\end{tabular}

$\left(\mathrm{Na}_{2} \mathrm{O}+\mathrm{K}_{2} \mathrm{O}-\mathrm{CaO}\right)$, de Frost et al. (2001), elas alocam-se essencialmente no campo das suítes álcali-cálcicas com enclave do SP no campo alcalino e outro do SASF no campo cálcica-alcalina (Figura 11C). As rochas desses stocks correspondem igualmente a magmatismo magnesiano característico de fonte de ambiente orogênico (Figura 11D).

As rochas dos stocks são metaluminosas, com amostras mais diferenciadas fracamente peraluminosas $(1<\mathrm{A} / \mathrm{CNK}$ $<1,1$; Figura 11E), nas quais coríndon normativo chega a $0,9 \%$ (Tabela 2). As amostras posicionam-se igualmente no campo dos granitos do Tipo I e grande parte das rochas do SP e do SFA ocupa a área de superposição dos campos dos granitos pós-colisionais e de arcos vulcânicos definidos por Maniar e Picolli (1989). As rochas do SASF ocupam a região entre os campos dos granitos pós-colisionais e de arco vulcânico (Figura 11D), área onde se alocam igualmente as rochas de outros stocks do Domínio Macururé com afinidade shoshonítica (Figura 11D).

As rochas estudadas apresentam valores moderados de Ba (639-1441 ppm), Sr (460-567 ppm), Zr (159-223 ppm),
Th (7-14,8 ppm) e Ga (22-37 ppm), e baixos de $\mathrm{Nb}$ $(4,7-11,2 \mathrm{ppm}), \mathrm{Y}(4-12 \mathrm{ppm}), \mathrm{Ta}(0,4-0,7 \mathrm{ppm}), \mathrm{Ni}$ (2-10 ppm) e Co (3,7-18 ppm). Esses valores são compatíveis com termos diferenciados de magmas com assinatura de fonte de arco.

O total dos ETR nas rochas é moderado e varia de 127,78 e 218,22 ppm. Os espectros de ETR das rochas dos diferentes stocks apresentam padrões semelhantes (Figura 12), e o SP apresenta-se com menor conteúdo de ETR. Esses espectros caracterizam-se por fracionamento dos ETR Leves em relação aos ETR Pesados $\left(46<\mathrm{La}_{\mathrm{N}} / \mathrm{Yb}_{\mathrm{N}}<79\right)$ e fracas anomalias em Eu situadas entre 0,76 e 1,06 (Figura 12). Nos enclaves têm-se menor grau de fracionamento dos ETR, 14,28 (SGP) e 17,94 (SASF), devido aos conteúdos mais elevados de $\mathrm{Yb}$ (Tabela 2), quando comparados às rochas hospedeiras.

No SP e no SASF, os enclaves quartzo monzoníticos apresentam maior conteúdo de Rb, Nb, P, Zr, Hf, Ti, Tb, Y, $\mathrm{Tm}$ e $\mathrm{Yb}$ que os granitos encaixantes. Todavia, esses dois grupos de rochas apresentam, como as demais rochas dos 
stocks, picos nos large-ion lithophile element e vales pronunciados em Nb, Ta, Ti e moderados em P (Figura 13). Esses espectros indicam que essas rochas formaram-se a partir de magmas gerados em ambiente de subducção.

Nos diagramas $\mathrm{Rb}$ versus $\mathrm{Y}+\mathrm{Nb}$ e Ta $+\mathrm{Yb}$ versus $\mathrm{Rb}$, as amostras dos stocks estudados alocam-se sobre ou na interface entre os magmas gerados em ambiente de arco vulcânico e os sincrônicos à colisão (Figura 13). As rochas do SASF e do SFA posicionam-se no campo dos magmas pós-colisionais (Figura 13).

\section{CONCLUSÕES}

As rochas dos stocks deste estudo truncam a foliação regional e apresentam texturas ígneas, indicando que não foram afetadas pela deformação predominante.

Os enclaves máficos microgranulares nos stocks apresentam composições variando de monzonítica a sienítica. Esses enclaves centimétricos a métricos apresentam contatos bem definidos, com geometrias curvas e ameboides,

Tabela 3. Análises químicas dos elementos-traço (em ppm) representativas de rochas dos stocks estudados. As amostras com asteriscos correspondem aos enclaves.

\begin{tabular}{|c|c|c|c|c|c|c|c|c|c|}
\hline & FDS-516A & FDS-516B & $\begin{array}{c}\text { FDS- } \\
\text { 516D1* }\end{array}$ & FDS-516F & GeSe522A & GeSe399A & $\mathrm{GeSe} 99 \mathrm{~B}^{\star}$ & GeSe400 & GeSe598 \\
\hline & Sp & $\mathrm{Sp}$ & $S p$ & $\mathrm{Sp}$ & $\mathrm{Sp}$ & SAF & SAF & SAF & SFA \\
\hline $\mathrm{Ba}$ & 897 & 1183 & 639 & 1207 & 1214 & 1481 & 823 & 1453 & 1260 \\
\hline $\mathrm{Rb}$ & 132,5 & 155,5 & 228 & 134,3 & 179,7 & 146,1 & 121,6 & 144,9 & 158 \\
\hline $\mathrm{Sr}$ & 660,3 & 573,9 & 462,2 & 637 & 632,6 & 690,5 & 517,5 & 653,1 & 687,9 \\
\hline $\mathrm{Zr}$ & 188,9 & 159,5 & 238,9 & 174,3 & 169,9 & 223,2 & 184,5 & 196,7 & 195,9 \\
\hline $\mathrm{Nb}$ & 4,7 & 5,6 & 11,8 & 5,5 & 6,6 & 11,1 & 11,2 & 9,1 & 9,02 \\
\hline $\mathrm{Ni}$ & 2,9 & 4,4 & 10,7 & 3,9 & 4,3 & 8,2 & 19,9 & 5,5 & 2,7 \\
\hline Co & 3,8 & 4,2 & 8,6 & 4,4 & 4,8 & 10,1 & 18,5 & 6,7 & 3,7 \\
\hline $\mathrm{Zn}$ & 69 & 70 & 202 & 75 & 75 & 88 & 73 & 72 & 75 \\
\hline Y & 4 & 4,4 & 8,4 & 4,2 & 5,4 & 12,3 & 18 & 8,8 & 5,29 \\
\hline Cs & 12,4 & 10,5 & 24,5 & 7,6 & 10,6 & 5,9 & 4,4 & 5 & 8,87 \\
\hline Ta & 0,4 & 0,6 & 0,6 & 0,3 & 0,4 & 0,7 & 0,7 & 0,6 & 0,5 \\
\hline $\mathrm{Hf}$ & 5,6 & 4 & 7,2 & 4,6 & 5,2 & 6,3 & 5,2 & 6,2 & 6,08 \\
\hline $\mathrm{Ga}$ & 24,4 & 26,5 & 37,6 & 23,5 & 27 & 25,9 & 22,5 & 25,2 & 26,4 \\
\hline Th & 11,7 & 7,7 & 11,2 & 10,1 & 11,2 & 14,8 & 9,5 & 12,9 & 11,3 \\
\hline$\cup$ & 3,2 & 3,2 & 6,6 & 2,8 & 3,3 & 3,5 & 3,3 & 3 & 2,56 \\
\hline V & 100 & 39 & 124 & 47 & 40 & 89 & 151 & 63 & 33 \\
\hline $\mathrm{Cu}$ & 17 & 13,6 & 11,2 & 10,1 & 2,6 & 11,2 & 15,3 & 8 & 6,7 \\
\hline $\mathrm{Pb}$ & 8,7 & 5,5 & 6,9 & 6,5 & 10,2 & 3,8 & 2,6 & 3,2 & 7 \\
\hline La & 39,1 & 27,4 & 19,7 & 31,6 & 29,6 & 47 & 34,6 & 39,2 & 35,4 \\
\hline $\mathrm{Ce}$ & 66,7 & 55,5 & 42,5 & 61,3 & 59 & 97,7 & 75 & 80,8 & 67,9 \\
\hline $\operatorname{Pr}$ & 7,34 & 5,89 & 5,05 & 6,98 & 6,96 & 10,92 & 8,7 & 8,88 & 8,49 \\
\hline $\mathrm{Nd}$ & 26,1 & 23,1 & 20,5 & 27,8 & 26,2 & 42,8 & 34,9 & 34 & 32,1 \\
\hline $\mathrm{Sm}$ & 3,18 & 3,54 & 3,91 & 4,23 & 4,41 & 7,44 & 6,57 & 5,84 & 5,7 \\
\hline $\mathrm{Eu}$ & 0,66 & 0,95 & 0,91 & 1,15 & 1,03 & 1,73 & 1,54 & 1,34 & 1,06 \\
\hline $\mathrm{Gd}$ & 1,86 & 2,89 & 2,75 & 2,62 & 2,49 & 4,96 & 5,13 & 3,7 & 3,15 \\
\hline $\mathrm{Tb}$ & 0,19 & 0,3 & 0,34 & 0,3 & 0,31 & 0,64 & 0,74 & 0,48 & 0,4 \\
\hline Dy & 0,83 & 1,25 & 1,58 & 1,25 & 1,19 & 2,75 & 3,72 & 2 & 1,44 \\
\hline $\mathrm{Ho}$ & 0,15 & 0,16 & 0,3 & 0,19 & 0,15 & 0,39 & 0,62 & 0,28 & 0,19 \\
\hline Er & 0,37 & 0,41 & 0,69 & 0,33 & 0,38 & 0,9 & 1,55 & 0,63 & 0,35 \\
\hline $\mathrm{Tm}$ & 0,06 & 0,04 & 0,1 & 0,05 & 0,05 & 0,13 & 0,23 & 0,1 & $<0,05$ \\
\hline Yb & 0,4 & 0,3 & 0,93 & 0,37 & 0,28 & 0,76 & 1,3 & 0,57 & 0,3 \\
\hline $\mathrm{Lu}$ & 0,06 & 0,05 & 0,14 & 0,03 & 0,04 & 0,1 & 0,2 & 0,08 & $<0,05$ \\
\hline
\end{tabular}



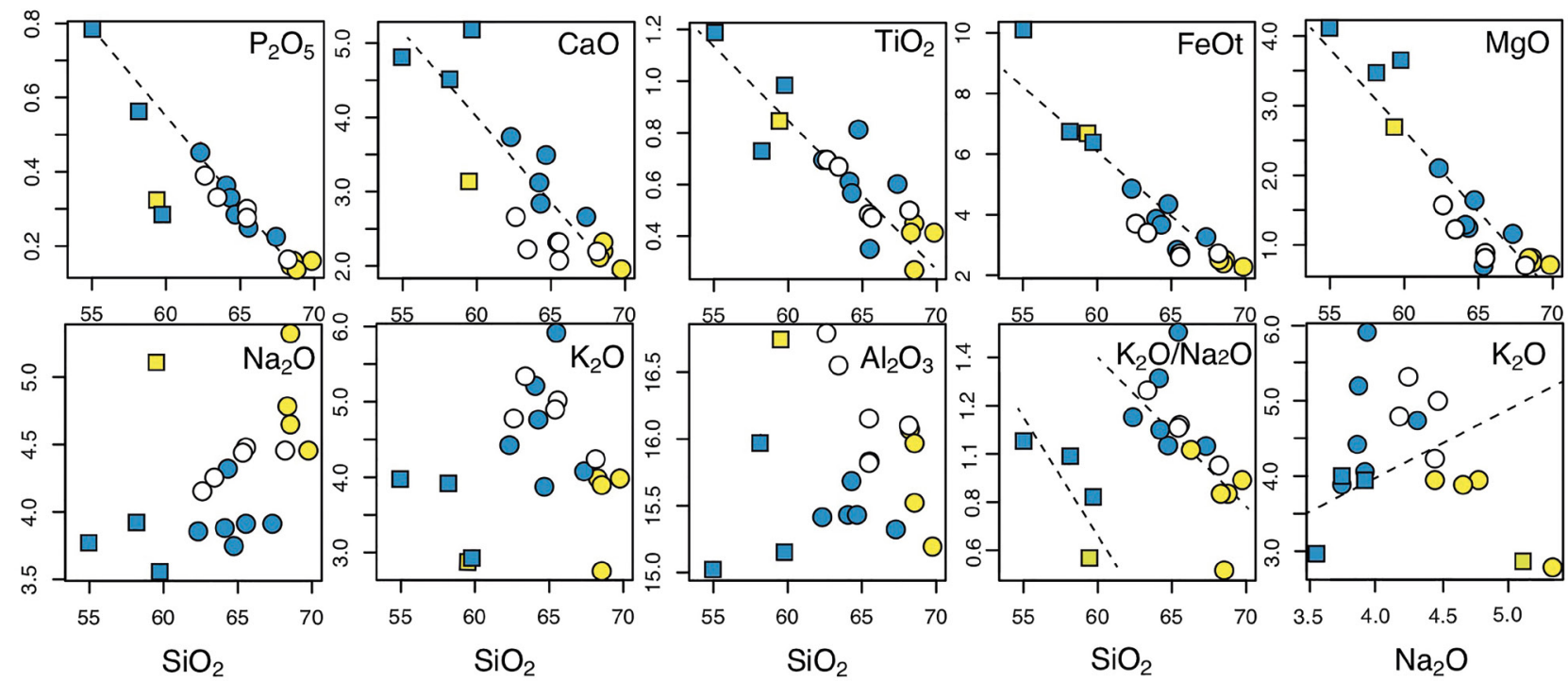

Figura 10. Diagramas de Harker com as rochas dos stocks estudados. Símbolos quadrados: enclaves. Círculos, rochas dominantes nos Stocks: Propriá, amarelo; Amparo de São Francisco, azul; Fazenda Alvorada, branco.

evidenciando a coexistência entre magmas básicos e intermediários-ácidos no SP e no SASF. A presença de granulação mais fina nos enclaves (Didier e Barbarin, 1991) e de cristais aciculares de apatita (Wyllie et al., 1962) e esqueléticos de biotita (Hibbard, 1991) sugere que essas rochas foram submetidas a período com elevada taxa de resfriamento. As zonações complexas em cristais de plagioclásio reforçam essa hipótese de coexistência e mistura entre magmas e indicam período de mudanças importantes de temperatura na evolução dos magmas basálticos nesses corpos. O conjunto de feições e texturas é interpretado como reflexo de episódio(s) de intrusão(ões) de magma(s) basáltico(s) responsável(is) pela geração dos enclaves.

A idade $\mathrm{U}-\mathrm{Pb}_{\text {Shrimp }}$ em zircão de $615 \pm 6 \mathrm{Ma}$ obtida para o SP corresponde à idade de cristalização e torna esse stock correlacionável ao magmatismo sincrônico à colisão que ocorre nos terrenos do Maciço Pernambuco-Alagoas, situado ao norte do SOS.

No conjunto dos stocks estudados, o de Propriá mostra-se o mais evoluído, sendo constituído por granitos com enclaves sieníticos. O SASF e o SFA são formados essencialmente por quartzo monzonitos, com quartzo monzodiorito subordinado, tendo como enclaves quarto monzodiorito, quartzo sienito e sienito. A mineralogia e a ordem de cristalização nas rochas dos stocks são semelhantes, o que está sendo interpretado como cogeneticidade. Nessas rochas a biotita é o máfico dominante, hornblenda ocorre em alguns enclaves e os minerais essenciais são plagioclásio (andesina e oligoclásio), feldspato alcalino pertítico e quartzo. Os minerais acessórios são: apatita, zircão, ilmenita, magnetita, pirita, monazita e allanita.
Os dados geoquímicos revelaram que as rochas estudadas correspondem a granitos do Tipo I, metaluminosos, potássicos de natureza shoshonítica (SASF e SFA), e cálcio-alcalina de alto $\mathrm{K}_{2} \mathrm{O}(\mathrm{SP})$. Os termos mais evoluídos mostram-se fracamente peraluminosos (coríndon $<1 \%$ ). Esse magmatismo é essencialmente magnesiano e com assinatura de ambiente de subducção (vales em Ta-Nb-Ti) em diagramas multielementares. A ausência de deformação nessas rochas é concordante com o seu posicionamento em diagramas de Pearce et al. (1984) no campo de magmas gerados em período pós-orogênico. Essas rochas mostram igualmente fracas anomalias em Eu, presente em magmas shoshoníticos (e.g., Nardi, 1986), e fracionamento dos ETR Leves em relação aos pesados é característico de magmas orogênicos profundos com retenção de granada na fonte (e.g., Wilson, 1989).

\section{AGRADECIMENTOS}

Os autores agradecem pelo suporte financeiro do Conselho Nacional de Desenvolvimento Científico e Tecnológico $(\mathrm{CNPq})$ e da Fundação de Apoio à Pesquisa e à Inovação Tecnológica do Estado de Sergipe (FAPITEC), processos de números 019.203.02538/2009-7 (PRONEX/FAPITEC/CNPq), 311008/2017-8 (CNPq-PQ), 310391/2017-2 (CNPq-PQ) e 311008/2017-8 (CNPq-Universal 2016). Ítalo Santana Santos foi bolsista de mestrado pela FAPITEC no Programa de Pós-Graduação em Geociências e Análise de Bacias da Universidade Federal de Sergipe. Externamos nossos agradecimentos às Dras. Cristina Maria Burgos Carvalho e Rita 

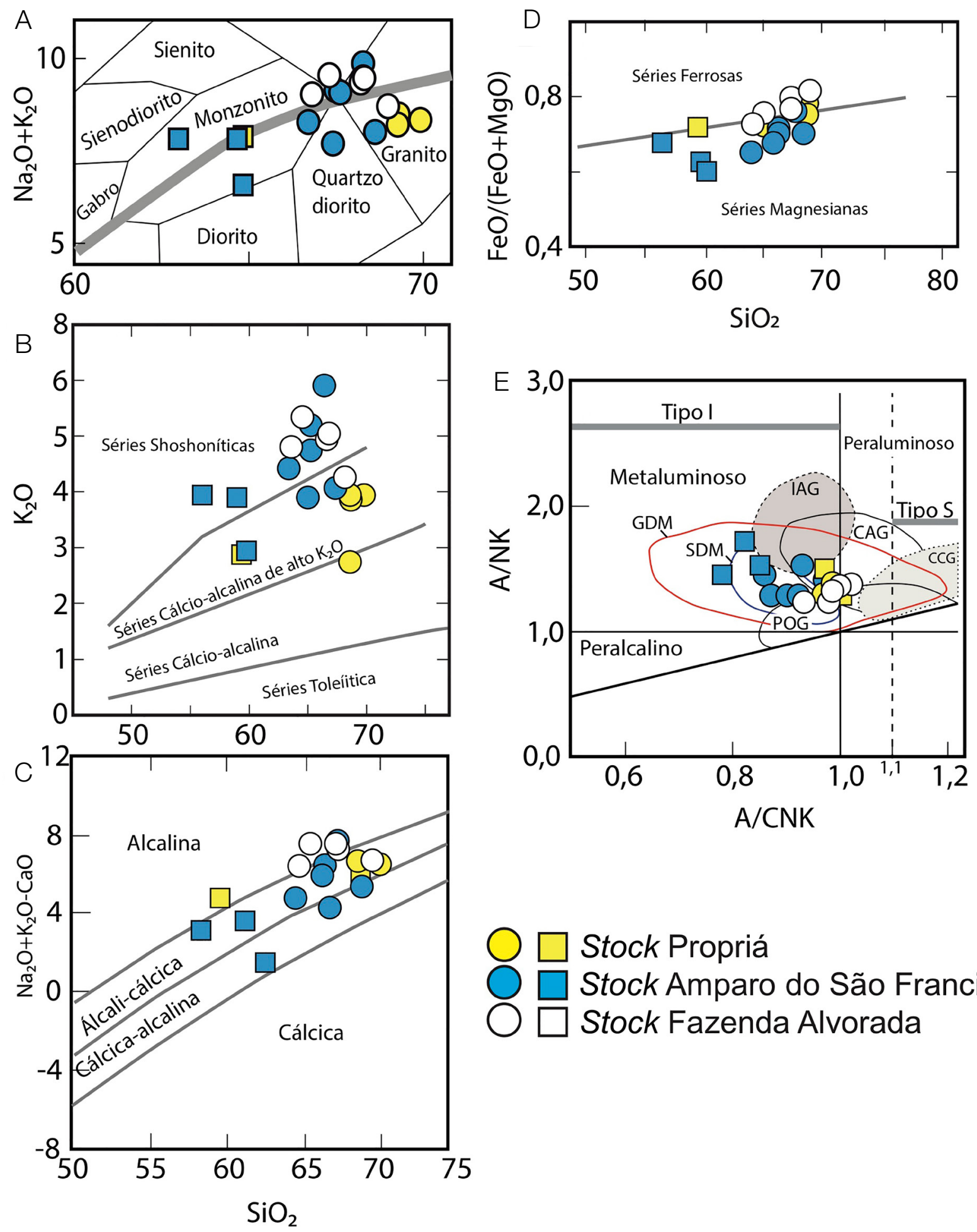

A/CNK

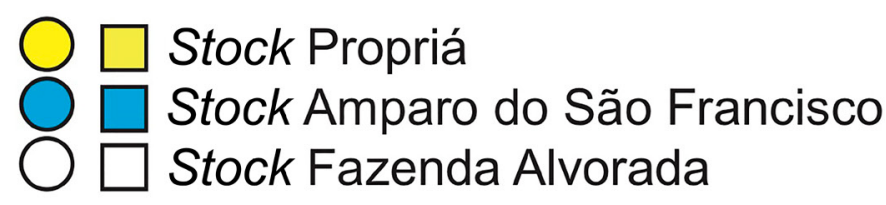

Figura 11. Diagramas geoquímicos mostrando a dispersão dos dados geoquímicos nos stocks estudados. Quadrados: enclaves. Círculos rochas dominantes nos stocks: Propriá, amarelo; Amparo de São Francisco, azul; Fazenda Alvorada,

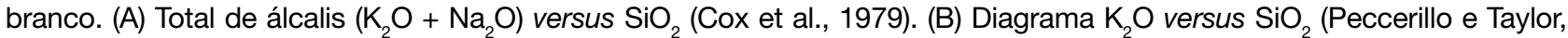
1976). (C) Diagrama MALI ( $\left.\mathrm{Na}_{2} \mathrm{O}+\mathrm{K}_{2} \mathrm{O}-\mathrm{CaO}\right)$ versus $\mathrm{SiO}_{2}$ (Frost et al., 2001). (D) Diagrama FeO/(FeO $\left.+\mathrm{MgO}\right)(\mathrm{Frost}$ et al., 2001). (E) Diagrama molecular $\mathrm{A} / \mathrm{NK}^{2}\left[\mathrm{Al}_{2} \mathrm{O}_{3} /\left(\mathrm{Na}_{2} \mathrm{O}+\mathrm{K}_{2} \mathrm{O}\right)\right]$ versus $\mathrm{A} / \mathrm{CNK}\left[\mathrm{Al}_{2} \mathrm{O}_{3} /\left(\mathrm{CaO}+\mathrm{Na}_{2} \mathrm{O}+\mathrm{K}_{2} \mathrm{O}\right)\right]$, de Maniar e Picolli (1989). Granitos de arco de ilhas (IAG), granitos de arco continental (CAG) e granitos de colisão continental (CCG); campos dos granitos (linha vermelha) e shoshonitos (linha azul) do Domínio Macururé (Conceição et al., 2016; Oliveira et al., 2017). 

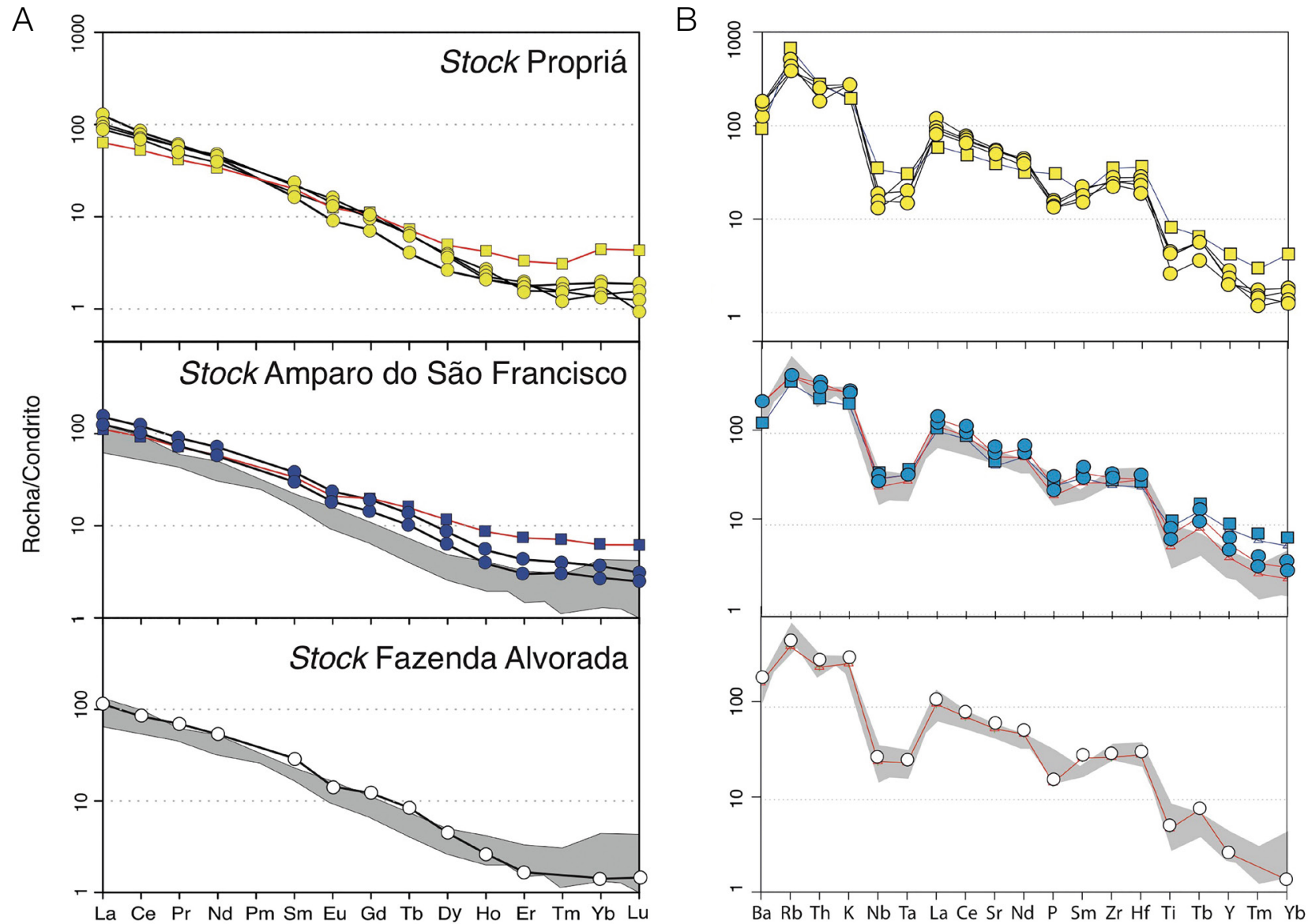

Figura 12. (A) Diagramas dos elementos terras raras das rochas estudadas normalizado pelo condrito de Byonton (1984). (B) Diagramas com elementos incompatíveis normalizados pelo condrito de Thompson (1982). A área cinza corresponde ao espectro do Stock Propriá.

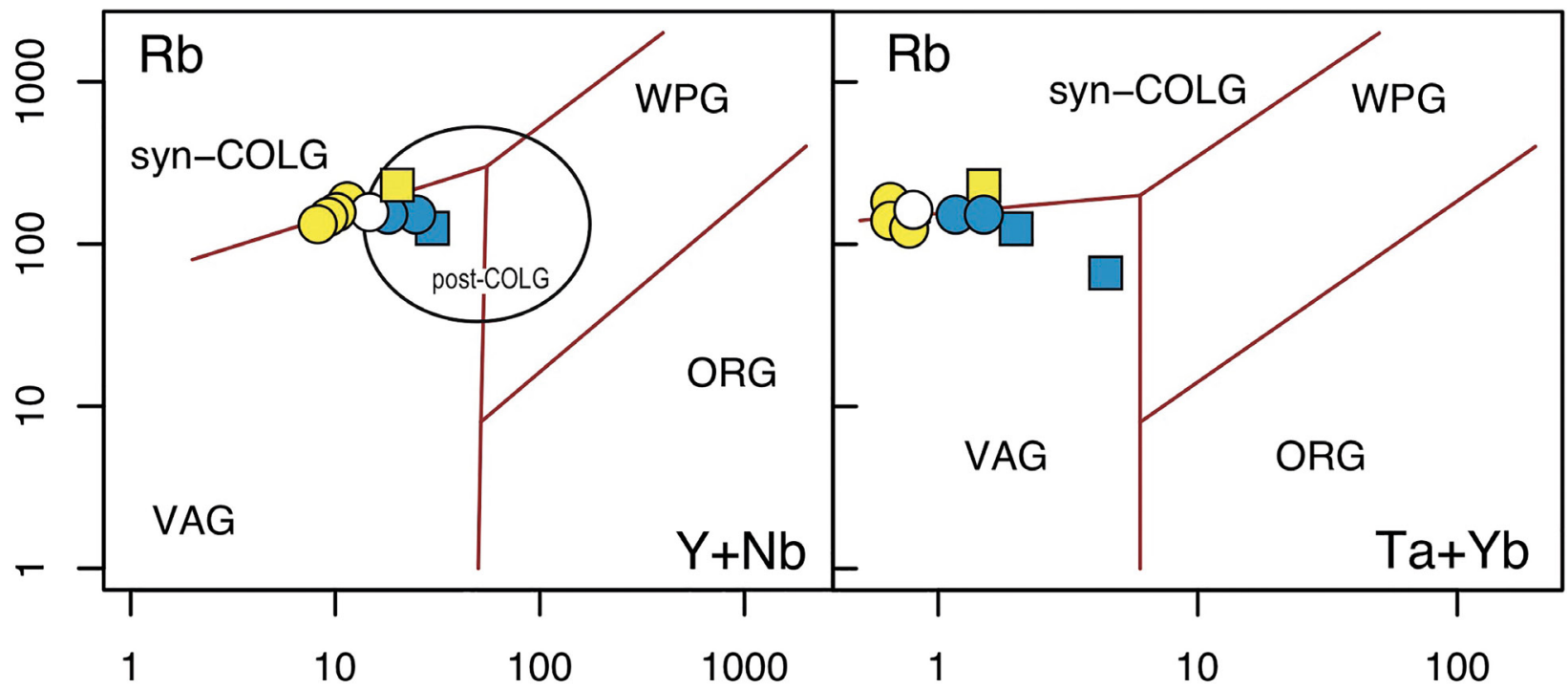

Figura 13. Diagramas de Pearce et al. (1984) e Pearce (1996) aplicado as rochas estudadas. Granitos sincrônicos a colisão (syn-COLG), granitos intraplaca (WPG), granitos de arcos vulcânicos (VAG) e granitos de cadeias meso-oceânicas (ORG). 
Cunha Leal Menezes, pesquisadoras da Superintendência de Salvador da CPRM, as discussões e as facilidades laboratoriais na preparação das amostras. Aos revisores deste texto, expressamos igualmente nossos agradecimentos pelas importantes contribuições.

\section{REFERÊNCIAS}

Almeida, F. F. M., Melcher, G. C., Cordani, U. G., Kawashita, K., Vandoros, P. (1968). Radiometric age determinations form Northem Brazil. Boletim da Sociedade Brasileira de Geologia, 17(1), 3-15.

Brito Neves, B. B., Cordani, U. G. (1973). Problemas Geocronológicos do "Geossinclinal Sergipano" e do seu embasamento. XXVI Congresso Brasileiro de Geologia, Anais, 1, p. 67-76. Aracaju: Sociedade Brasileira de Geologia.

Brito Neves, B. B., Fuck, R. A., Pimentel, M. M. (2014). The Brasiliano collage in South America: a review. Brazilian Journal of Geology, 44(3), 493-518. https://doi.org/10.5327/ z2317-4889201400030010

Bueno, J. F., Oliveira, E. P., McNaughton, N. J., Laux, J. H. (2009). U-Pb dating of granites in the Neoproterozoic Sergipano Belt, NE-Brazil: Implications for the timing and duration of continental collision and extrusion tectonics in the Borborema Province. Gondwana Research, 15(1), 86-97. https://doi.org/10.1016/j.gr.2008.06.003

Byonton, W. V. (1984). Geochemistry of the rare earth elements: meteorite studies. In: P. Henderson (Ed), Rare Earth Element Geochemistry, 63-114. Nova York: Elsevier,

Carvalho, M. J. (2005). Evolução Tectônica do Domínio Marancó-Poço Redondo: Registro das Orogêneses Cariris Velhos e Brasiliana na Faixa Sergipana, NE do Brasil. Tese (Doutorado). Campinas: Instituto de Geociências, UNICAMP.

Chayes, F. (1956). Petrographic modal analysis. Nova York: John Willy and Sons.

Compston, W., Williams, I. S., Meyer, C. (1984). U-Pb geochronology of zircons from Lunar Breccia 73217 using a sensitive, high mass resolution ion microprobe. Journal of Geophysical Research Atmospheres, 89(S02), B525-B534. https://doi.org/10.1029/JB089iS02p0B525

Conceição, J. A., Rosa, M. L. S., Conceição, H. (2016). Sienogranitos leucocráticos do Domínio Macururé, Sistema Orogênico Sergipano, Nordeste do Brasil: Stock Glória Sul.
Brazilian Journal of Geology, 46(1), 63-77. https://doi. org/10.1590/2317-4889201620150044

Cox, K. G., Bell, J. D., Pankhurst, R. J. (1979). The interpretation of igneous rocks. Boston: George Allen and Unwin.

Davison, I., Santos, R. A. (1989). Tectonic Evolution of the Sergipano Fold Belt, NE Brazil, during the Brasiliano Orogeny. Precambrian Research, 45(4), 319-328, 333-342. https://doi.org/10.1016/0301-9268(89)90068-5

Del'Rey Silva, L. J. H., McClay, K. (1995). Stratigraphy of the Southern of part of the Sergipano Belt, NE Brazil: Tectonic Implications. Revista Brasileira de Geociências, 25(3), 185-202. https://doi.org/10.25249/0375-7536.1995185202

Didier, J., Barbarin, B. (1991). Enclaves and Granite Petrology. Amsterdã: Elsevier.

Frost, R., Barnes, C. G., Collins, W. J., Arculus R. J., Ellis, D. J., Frost C. D. (2001). A Geochemical Classification for Granitic Rocks, Journal of Petrology, 42(11), 2033-2048. https://doi.org/10.1093/petrology/42.11.2033

Gava, A., Nascimento, D. A., Vidal, J. L. B., Ghignone, J. I., Oliveira, E. P., Santiago Filho, A. L., Teixeira, W., Stanford, W. J. P., Ribeiro, A. G., Ribeiro, J. H. M. (1983). Geologia. In: Projeto RadamBrasil. Folha SC-24/25 - Aracaju/Recife (27-376). Rio de Janeiro: DNPM.

Gill, R., Ramsey, M. H. (1997). What a geochemical analysis means. In: R. Gill (Ed.). Modern Analytical Geochemistry: an introduction to quantative chemical analysis for earth, environemental and materials scientists (2-40). Singapura: Addison Wesley Longman.

Hibbard, M. J. (1991). Textural anatomy of twelve magmamixed granitoid systems. In: J. Didier, B. Barbarin (Eds.). Enclaves and granite petrology (431-444). Amsterdã: Elsevier. (Developments in Petrology, 4).

Humphrey, F. L., Allard, G. O. (1969). Geologia da área do Domo de Itabaiana (Sergipe) e sua relação com a geologia do geossinclinal de Propriá: um elemento tectônico recém-reconhecido no escudo brasileiro. Rio de Janeiro: Petrobras/Cenpes, Divisão de Documentação Técnica e Patentes, $160 \mathrm{p}$.

Janoušek, V., Erban, V., Farrow, C. M. (2008). Geochemical Data Toolkit for Windows (GCDkit) 2.3. Disponível em: $<$ http://www.gcdkit.org/download $>$. Acesso em: fev. 2018. 
Jardim de Sá, M. F., Legrand, J., Hackspacher,P.C. (1981). Contraste de estilos estruturais e metamórficos na Faixa de dobramento Sergipana. Revista Brasileira de Geociências, 11(2), 128-137.

Lisboa, V. A. C. (2014). Petrologia e geocronologia do Maciço Glória Norte, Faixa de Dobramentos Sergipana, NE do Brasil. Dissertação (Mestrado). São Cristóvão: Programa de Pós-Graduação em Geociências, UFS.

Long, L. E., Castellana, C. H., Sial, A. N. (2005). Age, origin and cooling history of the Coronel João Sá Pluton, Bahia, Brazil. Journal of Petrology, 46(2), 255-273. https://doi. org/10.1093/petrology/egh070

Ludwig, K. (2009). Squid 2: a user's manual. Berkeley: Berkeley Geochronology Center, Special Publication.

Maniar, P. D., Picolli, P. M. (1989). Tectonic discrimination of granitoids. Geological Society of American Bulletin, 101(5), 635-643. https://doi.org/10.1130/0016-7606(1989)101\%3C06 35:TDOG\%3E2.3.CO;2

Mendonça, L. H. (2016). Contribuição a petrologia dos stocks graníticos nos municípios de Canhoba e Aquidabã, $N E$-Sergipe. Dissertação (Mestrado). São Cristóvão: Programa de Pós-Graduação em Geociências, UFS.

Nardi, L. V. S. (1986). As rochas granitoides da Série Shoshonítica. Revista Brasileira de Geociências, 16(1), 3-10.

Oliveira, E. P., Tarney, J. (1990). Petrogenesis of the Canindé de São Francisco Complex: a major late Proterozoic gabbroic body in the Sergipe Fold Belt, northeastern Brazil. Journal of South American Earth Sciences, 3(2-3), 125-140. https:// doi.org/10.1016/0895-9811(90)90025-V

Oliveira, E. P., Windley, B. F., Araújo, M. C. (2010). The Neoproterozoic Sergipano Orogenic Belt, NE Brazil: a complete plate tectonic cycle in western Gondwana. Precambrian Research, 181(1-4), 64-84. https://doi.org/10.1016/j.precamres.2010.05.014

Oliveira, E. P., Windley, B. F., McNaughton, N. J., Bueno, J. F., Nascimento, R. S., Carvalho, M. J., Araújo, M. C. (2017). The Sergipano Belt. In: M. Heilbron, U. G. Cordani, F. Alkmin (Eds.). São Francisco Craton, Eastern Brazil. Regional Geology Reviews, 241-254. Suíça: Springer. https:// doi.org/10.1007/978-3-319-01715-0_13

Pearce, J. A. (1996). A user's guide to basalt discrimination diagrams. In: D. A. Wyman (Ed.). Trace Element Geochemistry of Volcanic Rocks: Applications for Massive Sulphide Exploration, 79-113. St. Newfoundland: Geological Association of Canada. (Geological Association of Canada, Short Course Notes, 12).
Pearce, J. A., Harris, N. B. W., Tindle, A. G. (1984). Trace elements discrimination diagrams for the tectonic interpretation of granitic rocks. Journal of Petrology, 25(4), 956-983. https://doi.org/10.1093/petrology/25.4.956

Peccerillo, A., Taylor, S. R. (1976). Geochemistry of Eocene calc-alkaline volcanic rocks from the Kastamonu Area, Northern Turkey. Contributions to Mineralogy and Petrology, 58(1), 63-81.

Pereira, F. B. (2017). Contribuição à Petrografia e Geoquímica do Stock Amparo do São Francisco, Sistema Orogênico Sergipano. Monografia (Trabalho de Conclusão de Curso). São Cristóvão: Departamento de Geologia, UFS.

Rosa, M. L. S., Conceição, J. A., Lisboa, V. A. C., Silva, C. C., Pereira, F. S., Conceição, H. (2017). U-Pb zircon ages in granites (940-583 Ma) in the Sergipano Orogenic System, NE Brazil. 2017 Goldschmidt Conference. Paris: IAGC.

Santos, R. A., Martins, A. A., Neves, J. P., Leal, R. A. (2001). Geologia e Recursos Minerais do Estado de Sergipe. Texto Explicativo do Mapa Geológico do Estado de Sergipe. Escala 1:250.000. Brasília: CPRM, Convênio CPRM - CODISE.

Santos, R. A., Menezes, F., Dalton de Souza, N. R., Teixeira, L. R., Motta, A. C., Leal, R. A., Braz Filho, P. A. (1988). Geologia da Região Nordeste. Folhas Carira (SC.24-Z-AIII) e Jeremoabo (SC.24-Z-A-II). Estados da Bahia e Sergipe. Convênio DNPM/CPRM. Relatório Final. Brasília: CPRM. 8 v.

Sato, K., Tassinari, C. C. G., Basei, M. A. S., Siga Júnior, O., Onoe, A. T. (2014). Sensitive High Resolution Ion Microprobe (SHRIMP IIe/MC) of the Institute of Geosciences of the University of São Paulo, Brazil: analytical method and first results. Geologia USP. Série Cientifica, 14(3), 3-18. https://doi.org/10.5327/ Z1519-874X201400030001

Silva Filho, A. F., Guimarães, I. P., Santos, L., Armstrong, R., Van Schmus, W. R. (2016). Geochemistry, U-Pb geochronology, Sm-Nd and O isotopes of ca. $50 \mathrm{Ma}$ long Ediacaran High-K Syn-Collisional Magmatism in the Pernambuco Alagoas Domain, Borborema Province, NE Brazil. Journal of South American Earth Sciences, 68, 134154. http://dx.doi.org/10.1016/j.jsames.2015.12.013

Silva Filho, M. A. (1976). A suíte ofiolítica da Geossinclinal de Propriá. XXIX Congresso Brasileiro Geologia, 4, 51-58. Ouro Preto: SBG. 
Silva Filho, M. A., Bonfim, L. F. C., Santos, R. A. (1978). A Geossinclinal Sergipana: estratigrafia, estrutura e evolução. $X X X$ Congresso Brasileiro de Geologia, 6, 2464-2477. Recife: SBG.

Silva Filho, M. A., Bomfim, L. F. C., Santos, R. A., Santana, A. C., Filho, P. A. B., Leal R. A. (1979). Geologia da geossinclinal sergipana e do seu embasamento: Projeto Baixo São Francisco/Vaza Barris. Brasília: DNPM, 131 p. II.

Streckeisen, A. (1976). To each plutonic rock its proper name. Earth-Science Reviews, 12(1), 1-33. https://doi. org/10.1016/0012-8252(76)90052-0

Streckeisen, A. L., Le Maître, R. W. (1979). Chemical approximation to modal QAPF classification of the igneous rocks. Neues Jahrbuch fur Mineralogie, 136(2), 169-206.

Teixeira, L. R. (2014). Mapa Geológico do Estado de Sergipe. Escala 1:250.000. Salvador: Superintendência de Salvador do Serviço Geológico do Brasil (CPRM) e Companhia de Desenvolvimento Econômico do Estado de Sergipe (CODISE).
Thompson, R. N. (1982). Magmatism of the British Tertiary volcanic province. Scottish Journal of Geology, 18, 49-107. https://doi.org/10.1144/sjg18010049

Van Schmus, W. R., Oliveira, E. P., Silva Filho, A. F., Toteu, S. F., Penaye, J., Guimarães, I. P. (2008). Proterozoic links between the Borborema Province, NE, Brazil, and the Central African Fold Belt. Geological Society of London, Special Publication, 294, 66-69. https://doi.org/10.1144/SP294.5

Williams, I. S. (1997). U-Th-Pb geochronology by ion microprobe: not just ages but histories. Reviews in Economic Geology, 7, 1-35.

Wilson, M. (1989). Igneous Petrogenesis: A Global Tectonic Approach. Londres: Unwin Hyman.

Wyllie, P. J., Cox, K. G., Biggar, G. M. (1962). The habit of apatite in synthetic systems and igneous rocks. Journal of Petrology, 3(2), 238-243. https://doi.org/10.1093/ petrology/3.2.238 